\title{
Investment in Australian Aboriginal Art
}

\author{
Jenny Lye and Joe Hirschberg ${ }^{1}$
}

October 2020

\begin{abstract}
Recent changes in Australian legislation that limit the value of how artworks that can be considered as assets in retirement funds have had an impact on the Australian Aboriginal Art market. In this paper we estimate the impact of these changes on the price index based on prices paid for 15,845 works by over 200 artists at art auctions from 1986 to 2019 .

Using an OLS and a quantile regression approach, we estimate hedonic price models for various segments of the Australian Aboriginal art market. These models are used to estimate price indices in order to investigate if the changes in Australian laws concerning the sale and use of art assets has influenced the potential returns for different segments of the market.
\end{abstract}

Key words: resale royalties, art market price index, segmented price index, restrictions on assets for retirement funds

\footnotetext{
${ }^{1}$ Department of Economics, University of Melbourne, Melbourne 3010, AUSTRALIA.
} 


\section{Contents}

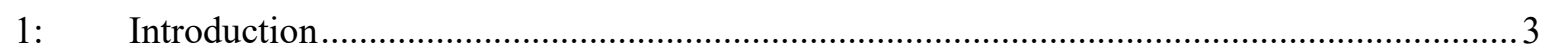

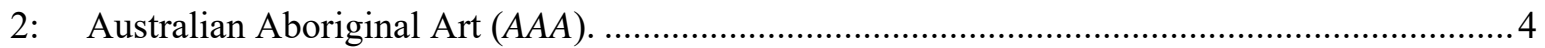

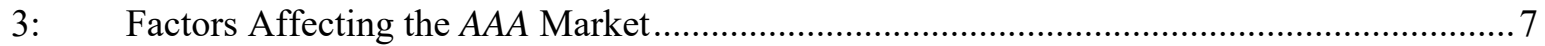

3:a 2018 Changes to the Protection of the Moveable Cultural Heritage Act 1986 (PMCH) ... 7

3:b Indigenous Australian Art Commercial Code of Conduct ................................................... 8

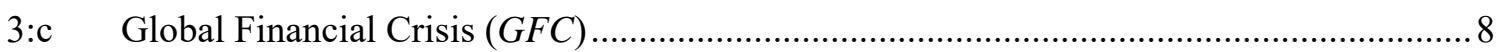

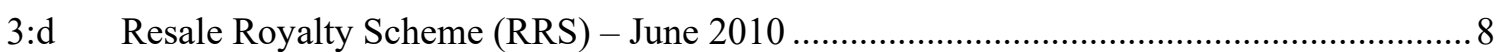

3:e Changes to self-managed superannuation funds July 2011 - July 2016 ........................... 9

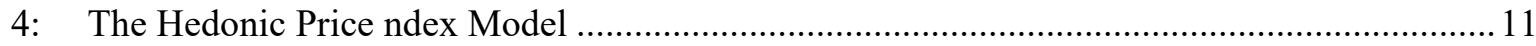

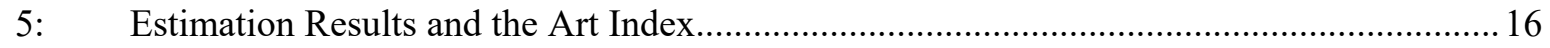

5:1 Estimating the Average Art Index using the OLS Model ................................................ 16

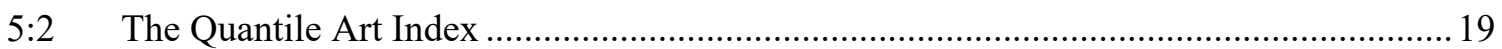

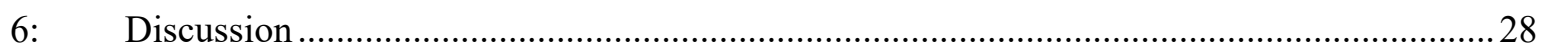

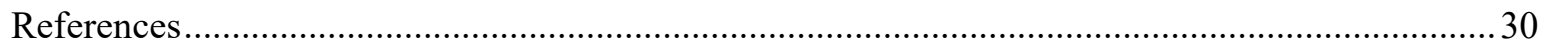

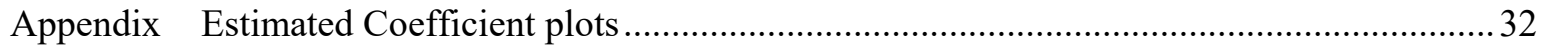

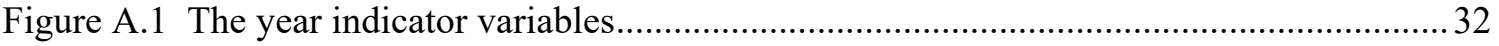

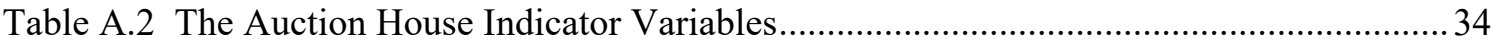

Figure A.3 The Repeat sales, Sold out of Australia, Sold after death and Telstra Awards

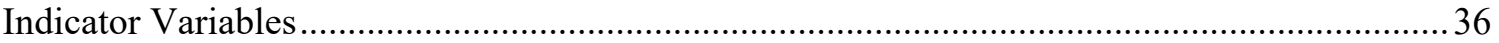

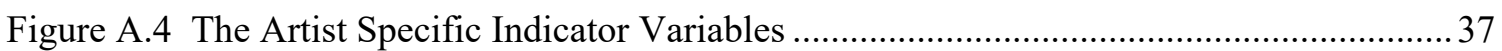




\section{1: Introduction}

In the past 10 years fine art has increasingly become an alternative investment asset for more than just high net wealth individuals. The Luxembourg office of the Deloitte consulting firm has promoted the consideration of art as financial asset in conjunction with more traditional assets such as equites, bonds, real estate and precious metals in a series of special reports on this alternative since 2011 (Deloitte and ArtTatic 2019). The increases in value of some portfolios of fine art have been measured as appreciating faster than many alternative traditional assets Etro and Stepanov (2019). The most recent estimate of the private holdings of art and collectables has been estimated as US\$1.742 trillion (page 27 Deloitte and ArtTatic 2019). In 2019 it has been estimated that global sales of art were US\$64.1 billion (page 1, McAndrew 2020) and since 2000 the increase in the price index for contemporary art has been approximately 300\% (Etro and Stepanov 2019).

The increased volume in the fine art market has attracted a greater degree of government regulation. In this paper we investigate the extent to which the sales of Australian Aboriginal Art ( $A A A)$ may have been influenced by the introduction of legislation in Australia. This legislation has changed three factors in the sale of $A A A$. First, the conditions under which it can be considered as an investment asset. Second, that removal from Australia may be limited when classified as cultural heritage. And third, that they are subject to royalty payments when resold.

The rest of the paper proceeds as follows. First, we provide a brief description of the rise of the contemporary $A A A$. Then, we provide a background of the current market in $A A A$ and the legislative actions that may have had an influence on the recent sales pattern. We then describe the hedonic price model we specify to account for characteristics of the art that can influence its sale price. We also include indicators for the dates when changes in legislation occur to determine if they have had a measurable influence on the sale price. We estimate this model with both the least-squares and quantile methods. The quantile approach allows us to accommodate different segments of the market and because of the wide variation in the prices of artworks in the sample. We compare the estimated price indices with the returns from traditional stock indices and the price indices that have been produced for the international market in contemporary art to determine how the market for $A A A$ compares. The final section presents conclusions and caveats to the results. 


\section{2: $\quad$ Australian Aboriginal Art (AAA).}

All Aboriginal societies share similar creation stories often referred to as 'the dreaming' or 'the dreamtime'. These explain the origin of the universe and the purpose of everything in it. Art is used to pass knowledge down through the generations. Initially these were depicted on rock walls, the body and in the sand. The present-day artwork on bark, canvas and board only commenced around 50 years ago. Aboriginal Artists need permission to paint particular stories and inherit the rights to these stories which are passed down through generations within certain skin groups. An Aboriginal artist cannot paint a story that does not belong to their clan. As Michael Nelson Tjakamarra, one of the well-known desert painters said, "Without the story the painting is nothing" (Genocchio 2008 pg. 96). Many women artists for example, paint stories associated with finding bush tucker such as bush potatoes, bush cabbage, honey ants and wild yams since women are the traditional principal food gatherers.

Until the 1970s Indigenous art was largely of ethnographic interest (Acker 2016). However, during the 1970s the beginnings of a commercial art market began and now for many residents of remote Indigenous Australian communities' art production is the principal non-welfare source of income. Typically, the artist's first or primary sale is through an agent whereas subsequent or secondary sales are most predominantly through an auction house. Only since the mid-1990s has there been a substantial secondary market for Aboriginal artwork (Genocchio 2008 pg 214). Primary and secondary markets are intricately linked as collectors are unlikely to spend significant amounts of money in the primary market if the artist does not have an established auction market. The most expensive Aboriginal artwork ever sold at auction was Clifford Possum Tjapaltjarri's painting Warlugulong $(1977)^{2}$ selling for $\$ 2.4$ million in $2007 .^{3}$ Prior to this it had been sold at auction in 1996 for $\$ 39,200$. Originally, Clifford Possum Tjapaltjarri sold Warlugulong (1977) for \$1,200 to a small art gallery where it was later bought by a bank and for twenty years it was hung in their cafeteria. ${ }^{4}$ Two months earlier in 2007, Emily Kame Kngwarreye's painting Earth's Creation

\footnotetext{
${ }^{2}$ It is quite common for Aboriginal Artists to name multiple work with the same name thus it is often necessary to use either numbering or dates to distinguish them.

${ }^{3}$ Unless otherwise noted the $\$$ amounts listed in this paper are in Australian dollars of the time. Note that for the period from 1987 to 2019 the average purchasing power parity rate was \$US .73 to \$AU 1.00. (OECD tables at https://data.oecd.org/conversion/purchasing-power-parities-ppp.htm.)

${ }^{4}$ See https://www.reuters.com/article/us-australia-art/aboriginal-masterpiece-sets-new-art-recordidUSSYD16281320070725
} 
I (1994) sold for \$1.056 million and more recently in 2017 for $\$ 2.1$ million. It is the most expensive piece of art by an Australian woman ever sold. ${ }^{5}$

It has been suggested that the rise of the Aboriginal art market in Australia began in the early 1980s, when museums began including the work in contemporary art shows. In 1981 the Art Gallery of New South Wales included work by Clifford Possum Tjapaltjarri and Tim Leura Tjapaltjarri in the inaugural edition of "Australian Perspecta," a biennial exhibition of contemporary Australian art that ran through 1999. ${ }^{6}$ Other major exhibitions by the Papunya Tula Artists have also drawn significant attention to Aboriginal art including the display at the World Expo '88 in Brisbane and a major retrospective exhibition in Sydney to coincide with the Sydney Olympics in 2000. The National Aboriginal and Torres Strait Islander Art Award started in 1983 and has become a significant annual showcase of contemporary Aboriginal art. Major exhibitions have also been held overseas. In 1988, "Dreamings: The Art of Aboriginal Australia", opened at the Asia Society in New York City and later moved to the David and Alfred Smart Gallery of the University of Chicago. The auction house Sotheby's has promoted Indigenous art in the global market since launching its stand-alone Aboriginal art auctions in 1997. In 1990, Rover Thomas and Trevor Nickolls exhibited their work at the Venice Biennale followed by Emily Kame Kngwarreye, Yvonne Koolmatrie and Judy Watson in 1997. In 2008 the exhibition Utopia: The Genius of Emily Kame Kngwarreye attracted over 120,000 visitors to the National Museum of Art in Osaka and the National Arts Center in Tokyo. ${ }^{7}$ In December 2019, Sotheby's held the first New York auction of Aboriginal contemporary art. The sale totaled US\$2.8 million and the most expensive painting sold was Emily Kame Kngwarreye's painting Celebration (1991) estimated at US\$300,000 to US\$400,000 and selling for US\$596,000. ${ }^{8}$

There are many different styles of Australian Aboriginal art. Aboriginal bark painting is a practice that goes back thousands of years and before the 1970s they were the most identifiable form of Aboriginal art. Today they are mainly associated with Arnhem Land and other regions in the Top End of Australia. The paintings can be drawn using different mediums showing aspects of Aboriginal life and most carry the sign of the clan, essentially naming the people responsible for the art. Cross hatching is often used and involves closely spaced fine lines drawn in particular colours, intersecting each other. The chosen colours

\footnotetext{
${ }^{5}$ See https://www.theguardian.com/artanddesign/2017/nov/17/emily-kame-kngwarreye-painting-sells-for-21min-sydney

${ }^{6}$ See https://www.artsy.net/article/artsy-editorial-driving-rise-aboriginal-art-market

7 See https://japan.embassy.gov.au/tkyo/indigenousarts.html

${ }^{8}$ See https://news.artnet.com/market/sothebys-new-york-first-aboriginal-sale-1733955
} 
may be specific to a clan. As bark paintings can warp and change shape over time they tend to not achieve as high a price as paintings on canvas.

Albert Namatjira was the most famous Aboriginal artists to work in a European style. He captured Australia's desert scenery in a European-watercolour style. He was born in 1902 and learnt to paint using watercolours while working as a 'camel boy' on painting exhibitions to central Australia in the 1930s with the Australian artist Rex Battarbee. His landscapes have now been evaluated as coded expressions on traditional sites and sacred knowledge. ${ }^{9}$ His style of work was adopted by other Indigenous artists in the region beginning with his close male relatives, and they became known as the Hermannsburg School.

The 'dot painting' style originating in the early 1970s has become one of the recognizable characteristics of Aboriginal art. An art teacher for the children in Papunya helped Aboriginal artists transfer depictions of their stories from desert sand to flat surfaces. However, the early paintings had few dots at all. Rather, they tended to be an accurate cursive style representation of cultural traditions and sometimes depicted sacred objects and secret information that was forbidden to be seen by the uninitiated. This provoked outrage and anger within the desert Aboriginal community once these paintings began to sell outside the settlement. The 'dot painting' style was developed to provide a more simplified iconography that was less revealing (Gennocchio 2008). Originally colours were restricted to variations of red, yellow, black and white produced from ochre, charcoal and pipe clay. Later acrylic mediums were introduced allowing for more vivid colourful paintings.

While in the 1970s the painting movement was largely confined to Papunya it developed rapidly in the 1980s. It is not a homogeneous entity. It differs in character and style depending from which region the artist is from and what language is spoken. The usual groupings are of art from the Central Australian desert; the Kimberley in Western Australia; the northern regions of the Northern Territory, particularly Arnhem Land, and northern Queensland, including the Torres Strait Islands.

Urban art is another distinct style of Indigenous art. This label emerged in the 1980s and includes Aboriginal artists from all metropolitan centres and suburbs across Australia, as opposed to Aboriginal artists living in rural or remote communities. These artists tend to work in a wide range of media and often the works are statements on contemporary social issues.

\footnotetext{
${ }^{9}$ See https://www.artgallery.nsw.gov.au/collection/artists/namatjira-albert/
} 
Taylor and Coleman (2011) construct an Aboriginal Art index for the period 1982 to 2007 using auction results for over 4,000 paintings for 50 Aboriginal artists with the greatest number of sales over this period. The index yielded an average annual return of $6.58 \%$ which was similar to other assets including $7.82 \%$ for the Australian Stock Exchange All Odinaires index and $8.47 \%$ for an Australian Real Estate index. Since this period though there has been a global financial crisis (GFC) and several changes to Government policy that may have had an impact on the Aboriginal Art market. In this paper we estimate an Aboriginal Art Index for the period 1986 to 2019 using a hedonic price equation based on auction results for over 15,000 artworks sales and 202 Aboriginal artists. The Aboriginal Art index we construct allows us to determine the influence of the GFC and changes to Government policy in this art market over this period.

\section{3: $\quad$ Factors Affecting the $A A A$ Market}

In this section we discuss several Government policy changes as well as the financial crisis of 2007-08, also known as the Global Financial Crisis (GFC) that may have had an impact on the Aboriginal Art market over the last 35 years.

\section{3:a 2018 Changes to the Protection of the Moveable Cultural Heritage Act 1986 (PMCH)}

This Act commenced operation on 1 July 1987 and was introduced to regulate the export of cultural objects from Australia. The legislation stated that fine art objects of Australian Aboriginal and Torres Strait Islander heritage required export permits if they were valued at $\$ 10,000$ or more and were of 20 years of age or more. ${ }^{10}$ It was thought that this Act had stymied the Aboriginal art market as it was capturing a significant amount of contemporary art. ${ }^{11}$

Changes to the legislation occurred in 2018. Several categories were introduced depending upon the type and age of the artwork. For example, any Australian Aboriginal desert paintings that does not include sacred and secret imagery painting and Aboriginal Kimberley paintings on canvas made for sale that are over 30 years and $\$ 100,000$ in value, require a permit for export. Works involving watercolours, sketches and drawings that are

\footnotetext{
${ }^{10}$ One example of a painting refused an export permit due to its significance as an object of fine art is Women's dreaming (1972) by Uta Uta Tjangala. Further, while the first-ever sale of Aboriginal art at Sotheby's London on June 2015 brought in over \$2 million for 75 lots, the auction was mostly drawn from the collection of Dutch billionaire Thomas Vroom which could only be sold because it predated this Act.

${ }^{11}$ See https://news.artnet.com/market/2-million-aboriginal-art-auction-pays-off-sothebys-london-307357
} 
over 30 years old and $\$ 40,000$ in value require a permit as well as any Aboriginal acrylic painting over $\$ 350,000$ in value. Aboriginal or Torres Strait Islander ochre paintings that are on bark, composition board, wood, cardboard, stone or other similar supports require a permit if they are 30 years of age or more and valued at $\$ 20,000$ or more. However, pre-1901 Aboriginal or Torres Strait Islander artworks valued at $\$ 25,000$ or more and pre-1960 Aboriginal or Torres Strait Islander bark paintings or sculptures valued at $\$ 25,000$ or more cannot be exported out of Australia. ${ }^{12}$ The changes were designed to allow "decisions to be made more quickly, cheaply, transparently, and certainly - while more effectively protecting Australia's most significant material" (Simpson 2015).

\section{3:b Indigenous Australian Art Commercial Code of Conduct}

The Code was officially launched on 29 November 2010 to specify a set of minimum standards for dealers, agents and artists, and defined terms of trade and rights and responsibilities for the sale and management of artworks. It is considered to not have had a major impact on the market as registration to the code was voluntary. ${ }^{13}$

\section{3:c $\quad$ Global Financial Crisis (GFC)}

GFC refers to the period of between mid-2007 and early 2009. It "impacted on people's appetite for art and it became a luxury spend" (Lamont 2011). During this crisis the global art market aggregate sales fell by over 37\% when they went from US\$62 billion in 2008 to US\$39 billion in 2009. By 2018 sales global sales had recovered to US\$67 billion (see Solimano 2019).

Higgs (2012) constructed an art price index based on works from 71 well-established Australian (including only 4 Indigenous) artists. She found this index was similar to the Australian stock market with a downturn in the middle of 2008 corresponding to the GFC. Further, she showed that during the GFC average art returns declined in nominal terms by close to six per cent with a standard deviation of twenty-one per cent.

\section{3:d $\quad$ Resale Royalty Scheme (RRS) - June 2010}

A resale royalty scheme in Australia was established with the intention of giving artists the right to receive a share in the financial profit from resales of their artworks. This

\footnotetext{
${ }^{12}$ See https://www.greeradamsfineart.com/news/exporting-aboriginal-art

${ }^{13}$ Details of the code can be found at https://indigenousartcode.org/the-indigenous-art-code/ and for a discussion on the impact see http://www.abc.net.au/worldtoday/content/2012/s3597288.htm
} 
scheme was particularly important for Aboriginal artists who lived in poverty while their artwork resold at high prices at auctions.

For example, Johnny Warangkula Tjupurrula (1925-2001) was a founding member of the Papunya Tula painting movement. While in the early 1980s his paintings frequently sold for $\$ 10,000$ by the mid-1980s he developed cataracts affecting the quality of his artwork. Most of the money he had made from the sales of his artwork he had given away to family and in 2001 he died without any possessions. However, while his painting Water Dreaming at Kalipinypa created in 1972 originally sold for $\$ 150$, in 1997 it sold at auction for $\$ 206,000$ and in 2000 for $\$ 486,500$. He received none of the proceeds of these higher sales (Gennocchio 2008).

The Resale Royalty Scheme came into effect on $9^{\text {th }}$ June 2010. This scheme entitles the artist to a 5\% royalty of the sales price of the artwork when it resells commercially for $\$ 1,000$ or more although, the artist is required to satisfy a residency test and if they are deceased the royalty is payable to beneficiaries who also meet the test. The royalty only applies on works that are sold during the life of the artist or within 70 years following their death. Between June 2010 - December 2019 more than $\$ 8$ million dollars has been generated for over 1,900 artists from 20,000 resales with most royalties being between $\$ 50$ and $\$ 500 .{ }^{14}$ However, for auctions, Wilson-Anastasios (2019) reports that two market auction houses, Deutscher and Hackett and Sotheby's, that account for almost half of Australia's auction turnover collected less than $\$ 70,00$ and $\$ 6,200$ for Indigenous artists respectively. Further, it has been suggested that auction houses may avoid the sale of low value transactions as a way to minimize the administrative burden of the scheme (Challis 2019).

\section{3:e Changes to self-managed superannuation funds July 2011 - July 2016}

Due to the increased use of art as an investment, national governments have found it necessary to codify the distinction between investment in art and collecting art in order to establish how art sales are considered under tax legislation. For example, the United States Internal Revenue Service (IRS) make a distinction for taxation purposes between the sale of pieces of fine art as either part of a personal collection or as the inventory of a gallery. In addition, the IRS does not allow investment in collectables to be considered in the portfolio of an Individual Retirement Account (IRA). ${ }^{15}$

\footnotetext{
${ }^{14}$ See www.resaleroyalty.org.au

${ }^{15}$ See details at: https://www.irs.gov/retirement-plans/investments-in-collectibles-in-individually-directedqualified-plan-accounts.
} 
Australian self-managed superannuation funds (SMSFs) are privately run investment funds that can currently have between 1 and 4 members who must also be trustees of their funds. The superannuation scheme in Australia allows individuals to shelter income for retirement in one of three forms of funds: Industry, Retail and SMSF. The SMSFs were defined in October 1999 from the former regime of "excluded" funds (funds with fewer than 5 members). As of March 2019, they accounted for $\$ 747$ billion or about $27 \%$ of all Australian superannuation funds ${ }^{16}$. Artwork can be included as investments held by the SMSFs with certain recent restrictions.

In a similar move to the US Internal Revenue Service, the Australian Taxation Office (ATO) declared that as of the end of June 2011 art collections cannot be used as assets in Self-Managed Superannuation Funds (SMSF) unless they satisfy the sole purpose test which implied that they are not to be displayed. The Australian legislature's Super System Review panel made the following comment on art as assets prior to the institution of this legislation:

that these investments (art) lend themselves to personal enjoyment and therefore
can involve current day benefits being derived by those using or accessing the
assets. The panel argued that these assets should not be regarded as investments
that build retirement savings and consequently should not be available to
SMSFs. ${ }^{17}$

From the first of July, 2011 trustees of SMSFs in which artworks were included were required to comply with a new set of rules regarding the storage, insurance and display of artworks. ${ }^{18}$ Thus, all artworks in SMSFs had to be stored externally to any premise in which the owner or related party lived or conducted business. The SMSFs could hire the artwork to a gallery for display purposes otherwise the artwork was required to be unseen. Investors were given five years from June 2011 to comply with the new set of rules or the artworks were to be sold. Prior to this ruling there were no such limitations as to the display of these artworks. At the time it was anticipated this change would have a significant impact on the Indigenous art market. In 2010 the managing director of Moss Green auctions estimated that around $60 \%$ of Indigenous art sales were made through SMSFs (Lehman-Schultz 2013). The impact of this ruling could be quite profound given that a recent global survey of the location of private art collections indicated that $60 \%$ are displayed in homes and offices (page 334 McAndrew 2020).

\footnotetext{
16 See the reference at: https://www.superguide.com.au/smsfs/smsfs-lead-the-super-pack-again.

17 Page 12, TAX LAWS AMENDMENT (2011 MEASURES No. 2) BILL 2011, https://parlinfo.aph.gov.au/parlInfo/download/legislation/ems/r4563 ems_2f20a3c1-8cc7-4b75-85911b729d64b92f/upload_pdf/353786.pdf;fileType=application\%2Fpdf

18 Where artworks are defined as painting, sculpture, drawing, engraving, photograph including reproductions.
} 


\section{4: $\quad$ The Hedonic Price ndex Model}

Most artists first sell their artwork through a gallery, an agent, using an online platform, through an art exhibition or fair and these sales are known as primary sales. The secondary or auction market represents the resale of paintings typically with artworks by artists who have a reputation. However, both the primary and secondary markets are linked. For example, if an artwork is sold at a low price on the secondary market, it can be detrimental to an artist's career and the value of future works.

In this paper, we analyze the auction results for the period 1986-2019 for 15,845 works by 202 Australian Aboriginal artists to investigate determinants of prices in the Aboriginal art market. The auctions are conducted as English-style or ascending bid auctions. In these auctions the auctioneer calls out increasingly higher prices and when no other bidder is prepared to exceed this price, the auctioneer strikes his hammer, and the painting is sold at this highest bid price provided this price exceeds the seller's reserve price. In addition to the hammer price the buyer must also pay the buyer's premium which is a fee that covers the associated costs of selling at auction houses. This fee can be up to $25 \%$ of the hammer price. The amount of the premium is stated in the auction house terms and conditions of sale.

For this analysis we adopt a hedonic price equation specification. Here we assume that prices received at auction are the market clearing price. In this model all sales (including repeat sales) are considered as single sales and are assumed to be determined by a bundle of characteristics, such as the name of the artist, size of the painting, medium and source of the painting, auction house, month and year of sale. These characteristics contribute to the utility derived from its ownership (Rosen 1974). The price of this bundle is assumed to equal the sum of the 'implicit' prices of the characteristics that constitute the artwork. The characteristics can only be bought in bundles and the price of the bundle, the hammer price and buyer's premium in this case, is observed. Court (1939) first proposed using a hedonic model to construct a price index. Since then this approach has been used to generate price indices for such diverse goods as: automobiles (Griliches 1961); pesticides (FerandezCornejo and Jans 1995); laptop computers (Chwelos 2003), US colleges (Schwartz and Scafidi 2004) and Australian private schools (Lye and Hirschberg 2017). This approach has also been used to construct price indices for the art market in numerous countries including Demir et al (2018) for Turkish paintings, Witkowska (2014) for Polish paintings, Higgs and 
Worthington (2005) and Higgs (2012) for Australian paintings, Renneboog and Van Houtte (2002) for Belgium paintings and Hodgson and Seçkin (2012) for Canadian paintings.

The dependent variable in the analysis is defined as the logarithm of the sale price (hammer price plus buyer's premium) of the $j$ th painting at time $t \log \left(P_{j t}\right)$ with a mean value of 8.10 and values ranging from a minimum of 2.40 and a maximum of 14.69 . We adopt a $\log$-linear specification in which $\log \left(P_{j t}\right)$ is modelled as

$$
\log \left(P_{j t}\right)=\alpha+\sum_{t=2}^{T} \rho_{t} D_{t}+\sum_{n=2}^{N} \beta_{n} A_{n}+\sum_{k=1}^{m} \alpha_{k} X_{j k t}+\varepsilon_{j t}
$$

where $D_{t}$ is a dummy variable that takes the value of one if a painting sold in period $t$ (and 0 otherwise), each artist is represented by a dummy variable defined as $A_{n}=1$ for artist $n$ (and 0 otherwise), $X_{j k t}$ represents the value of the characteristics, the number of periods is $T=34$ covering the period 1986-2019 and the number of artists is $N=202$.

The number of sales differ by year. The largest proportion of sales occurs in 2004 with $6.39 \%$ and the lowest in 1992 with $0.23 \%$. One of the most important factors determining the price of artwork is the reputation of the artist and the dummy variables $A_{n}$ are included in the model to account for the artists reputation and to proxy other characteristics of the artist such as the region they come from and the subject matter and style they paint. Figure 1 is a smoothed colour density representation of a scatterplot of the log prices ordered across the artists by descending values of the median. It highlights the wide range of sale prices obtained for each artist as well as across the 202 artists in the sample. Figure 2 plots the variation of the number of artworks sold across the 202 artists in the sample. The mean number of artworks sold is 78 and the smallest number sold by an artist in the sample is 3 and the maximum number is 845 . 
Figure 1: Scatterplot of the Logarithm of sale prices at auction by artists ordered by the median price

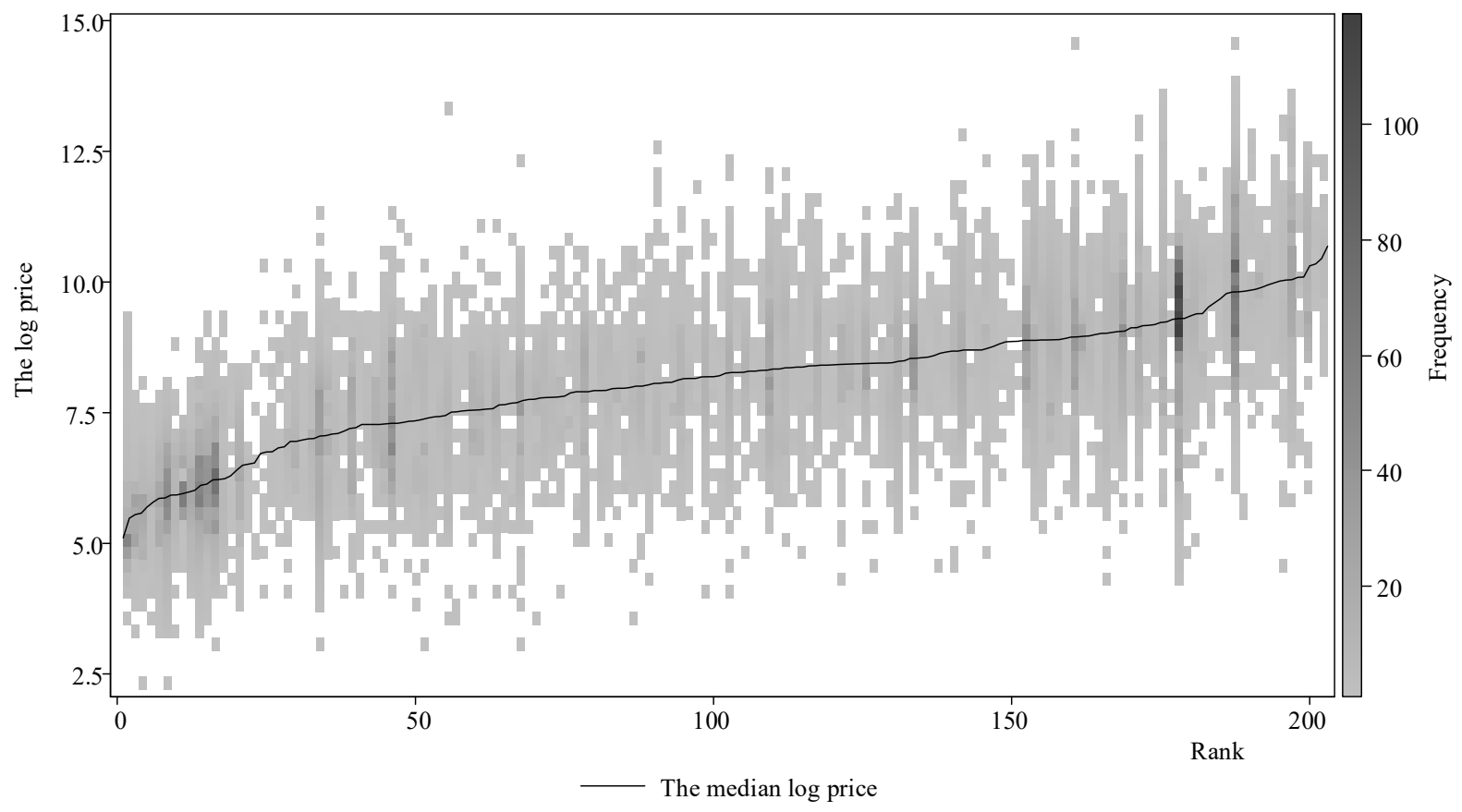

Figure 2: The distribution of the number of artworks sold at auction by artist. ${ }^{19}$

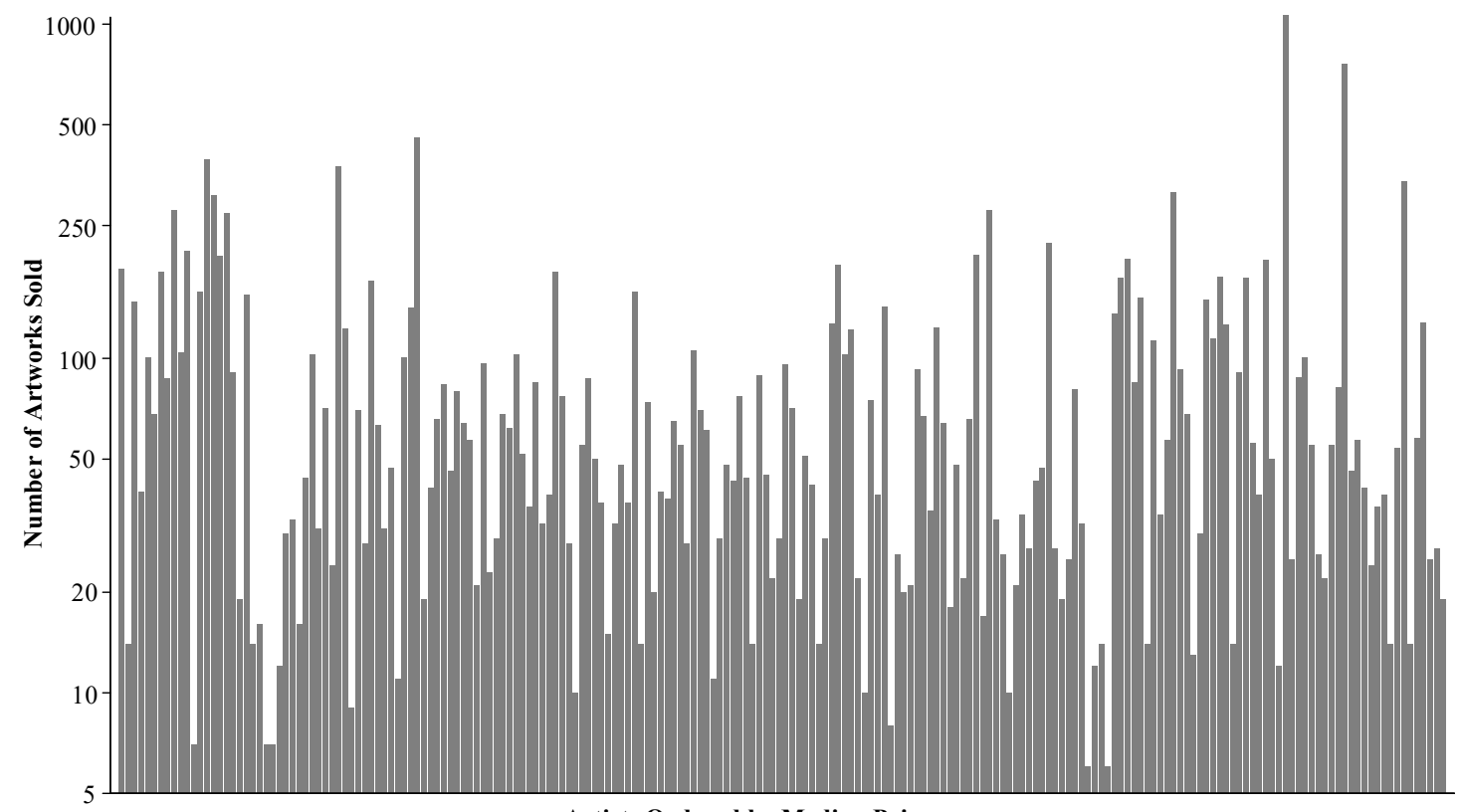

The other characteristics include the size of the painting as represented by the surface area in square meters (sqa) with mean $1.083 \mathrm{~m}^{2}$ and the surface area squared $\left(s q a^{2}\right)$. As the death of an artist caps the stock of paintings a dummy variable $(Y D)$ is included to indicate whether the artist is deceased at the time of the auction. On average the proportion of artists

19 Only one artist that has sold fewer than 5 pieces is not shown. 
living at the time of the auction is 0.38 and Figure 3 shows how this varies by each year of the sample. From this figure from 1994 on the number of works sold by living artists was quite a bit greater.

Figure 3: Proportion of artists that were living at the time of the auction

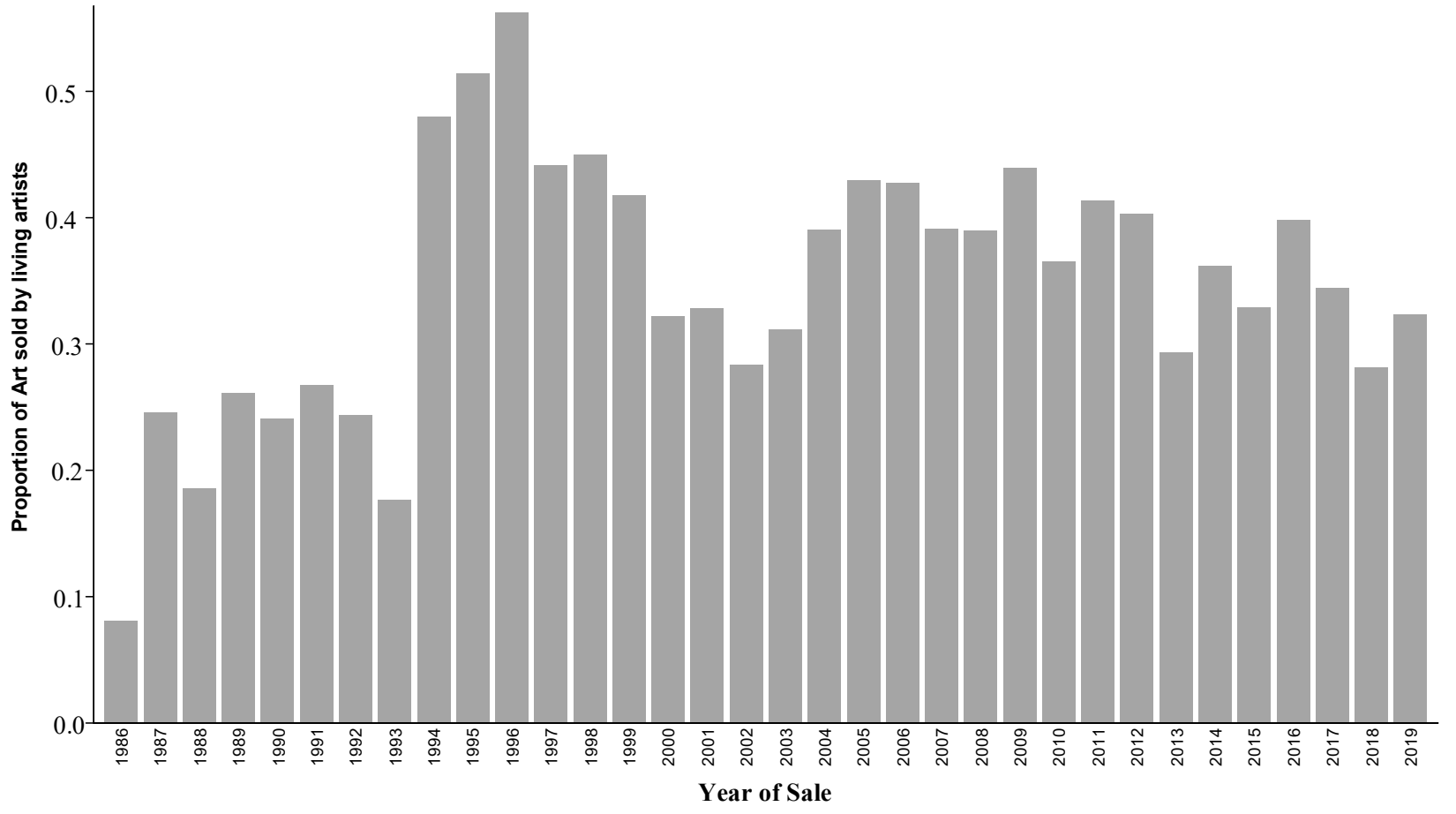

The Telstra National Aboriginal \& Torres Strait Islander Art Awards (NATSIAA) is Australia's longest running and most prestigious Indigenous art awards. A variable is included for every decade of the sample (1986-89, 1990-99, 2000-2009, 2010-2019) to indicate whether the artist had received one of these awards. For the period 1986-1989, $1.98 \%$ of the sample received these awards, $6.4 \%$ over the period $1990-1999,12.38 \%$ over the period 2000-2009 and 2.97\% over the period 2010-2019. Multiple awards were received by 3 artists with John Mawurndjul receiving 4 and both Paddy Fordham Wainburranga and Wingu Tingima receiving 2.

Dummy variables are included to indicate the surface used for the artwork (onwood (7.32\%), onbark (6.60\%), onpaper (4.15\%) and other) and to also identify the medium of the work as described in the database (acrylic (19.99\%), earth pigments (1.0\%), etching $(0.42 \%)$, linocut (0.9\%), mixed media (0.25\%), natural pigments (14.09\%), ochre (1.5\%), oil (1.75\%), 
pen $(0.13 \%)$, pencil $(0.14 \%)$, polymer paint $(0.10 \%)$, gouache $(0.45 \%)$, screenprint $(1.40 \%)$, synthetic polymer paint ${ }^{20}(33.27 \%)$, watercolour (23.42\%) and other.

Dummy variables are also included to account for the 44 auction houses where the sales take place. Figure 4 shows the distribution of total sales across the sample by the 27 auction houses with over $\$ 150,000$ in turnover. The market is dominated by Sotheby's ${ }^{21}$, Menzies and Deutscher and Hackett. ${ }^{22}$ For this sample, the highest proportion of sales occurred in October and the lowest in May. To account for seasonal fluctuations in sales, monthly dummy variables are included. Overseas sales account for $2.2 \%$ of the sales. A dummy variable is included to indicate whether the painting was sold at an auction that was held overseas (overseas). Although each painting is treated as a single sale, we also include a dummy variable to indicate whether the sale was a repeat sale (repeat). In the sample only $2.6 \%$ of the sales were identified as being repeat sales $^{23}$.

Figure 4: Distribution of Auction Turnover by House ${ }^{24}$

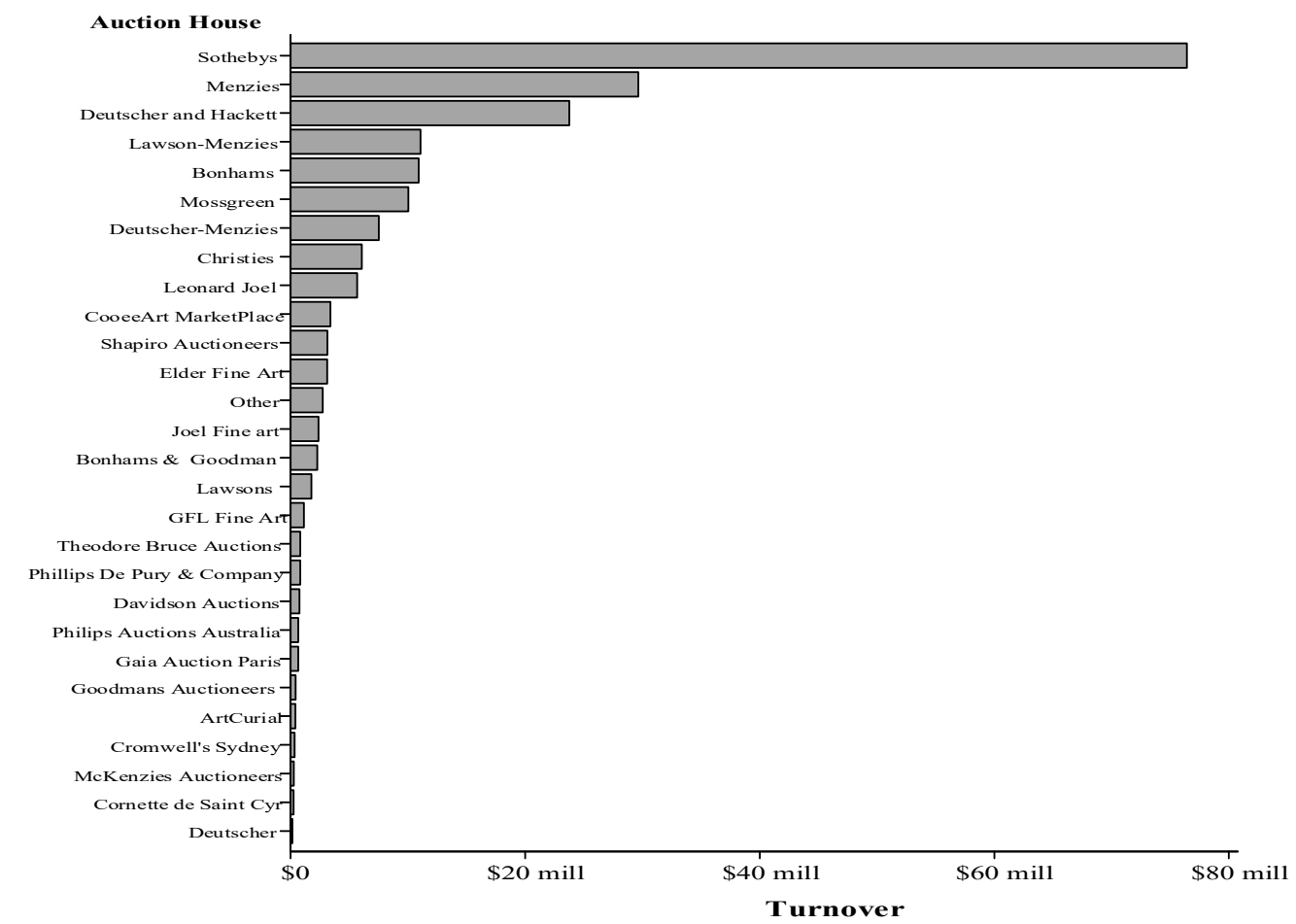

\footnotetext{
${ }^{20}$ Note that acrylic and synthetic polymer paints are identical. However, contemporary artists are labelling their paintings synthetic polymer paint rather than using the acrylic label due to a perceived difference in nomenclature see e.g. artistmarketingresources.com.

21 For example as noted by Cascone S. (2015).

${ }^{22}$ Note that in some cases the name of the auction house was not consistent, and we report the name as recorded.

23 Due to the lack of an indication that the work had been previously sold we determined if it was a repeat sale if the work had the same: title, artist, description of medium and dimensions, where the sales were at least 120 days apart.

24 The values are in nominal Australian dollars. The other category is the total for auction houses that have less than 150,000 in total turnover.
} 


\section{5: $\quad$ Estimation Results and the Art Index}

\section{5:1 Estimating the Average Art Index using the OLS Model}

The estimated OLS coefficients of the hedonic pricing regression model specified in (1) are presented in Table 1. To account for an unknown form of heteroskedasticity the standard errors and corresponding $p$-values are based on heteroskedastic-consistent standard errors. The adjusted $R^{2}$ is 0.732 and the four joint $F$-tests on the coefficients on the dummy variables for years, the dummy variables for month, the auction house dummy variables and the artists fixed effects are all rejected.

Table 1: OLS Estimation Results

\begin{tabular}{|c|c|c|c|}
\hline Variable & OLS & Variable & OLS \\
\hline Constant & $7.263 * * *$ & Synthetic & $1.344 * * *$ \\
\hline$Y D$ & $0.063 * *$ & Water & $0.656 * * *$ \\
\hline sqa & $0.049 *$ & Overseas & $0.582 * * *$ \\
\hline$s q a^{2}$ & $-4.6 \mathrm{E}-5 * *$ & Tel80 & $-2.14 * * *$ \\
\hline Onwood & $0.559 * * *$ & Tel90 & 0.053 \\
\hline Onbark & $-0.223 * * *$ & Tel00 & $0.17 * *$ \\
\hline Onpaper & $-0.285 * * *$ & Tel10 & 0.048 \\
\hline Acrylic & $0.801 * * *$ & Repeat & 0.042 \\
\hline Earth & $1.308 * * *$ & Fixed Effects & \\
\hline Etching & $-0.749 * * *$ & Years & Yes \\
\hline Linocut & $-1.094 * * *$ & Months & Yes \\
\hline Mixed & $0.904 * * *$ & Auction houses & Yes \\
\hline Natural & $1.29 * * *$ & Artists & Yes \\
\hline Ochre & $1.239 * * *$ & & \\
\hline Oil & $0.691 * * *$ & Observations & 15,845 \\
\hline Pen & -0.302 & $\bar{R}^{2}$ & 0.732 \\
\hline Pencil & 0.121 & $F$ tests (years) & $46.98 * * *$ \\
\hline Polymer & $1.049 * * *$ & $F$ tests (months) & $12.02 * * *$ \\
\hline Gouache & $0.256^{*}$ & $F$ tests (auction houses) & $53.26^{* * *}$ \\
\hline Screenprint & $-0.955 * * *$ & $F$ tests (artists) & $72.35 * * *$ \\
\hline
\end{tabular}

Notes: Dependent variable: logarithm of the sale price. The omitted year is 1986, omitted month is April, omitted artist is Rover Thomas, omitted auction house is Ainger, omitted medium is other and omitted surface is other. Significance levels: ${ }^{* * *} p<0.01,{ }^{* *} p<0.05,{ }^{*} p<0.1$ based on heteroskedastic-consistent standard errors.

From Table 1 it can be noted that if the artist is no longer living at the time of sale $(Y D)$ generates a positive effect on the price of the artwork as does sales in overseas auctions. While the surface area (sqa) has a positive effect on the price of the artwork, the squared term $\left(s q a^{2}\right)$ has a negative effect. This implies that there is an increase in the sales price associated with an increase in the artwork size but this impact diminishes with increasing size. A similar result was also found in Higgs and Worthington, (2005). In comparison to other mediums, acrylic, earth, mixed, natural, ochre, oil, polymer, gouache and synthetic are more expensive whereas etching, linocut, pen and screenprint are less expensive. Artworks on 
wood (onwood) are more expensive compared to artworks on other surfaces whereas those on bark (onbark) and on paper (onpaper) are less expensive. The results also suggest that artworks are more expensive for those who received Telstra National Aboriginal \& Torres Strait Islander Art Awards in the 2000's but less expensive in the 1980's.

The estimates of $\rho_{t}$ can be used to form an art price index conditioned on the other explanatory variables included in (1). The level of the art price index is defined as 100 for the year 1986. For subsequent years, the price index is computed by exponentiating the estimates of $\rho_{t}$. That is, the estimated price index for 1987 is $100 \exp \left(\hat{\rho}_{2}\right)$, at time 1988 is $100 \exp \left(\hat{\rho}_{3}\right)$ and up to 2019 which is $100 \exp \left(\hat{\rho}_{34}\right)$. A plot of the nominal art price index is shown in Figure 5. To provide a comparison with Australian financial assets also plotted in Figure 5 is the nominal All Ordinaires price index. As both art and housing can be considered as consumption and investment goods (Higgs 2012), the housing price index is also plotted. The All Ordinaires price index tracks the movements of the 500 largest companies listed on the Australian Securities Exchange (ASX) accounting for over 95\% of all the shares listed on the ASX and is used here to provide a comparison between the art market and Australian financial assets. The Australian housing price index is the weighted prices for eight Australian capital cities produced by the Australian Bureau of Statistics. ${ }^{25}$

Highlighted in Figure 5 are the periods of the GFC, the introduction of the RRS, the period of the self-managed superfund changes (SUPER) and the 2018 amendment to the Protection of the Moveable Cultural Heritage Act 1986 (PMCH). Over the sample period, we see that the housing price index has been steadily increasing with moderate falls in 2010 and more recently in 2019. The All Ordinaries stock index and Art Price indices had similar profiles up until the GFC and they also both fell during the period of the GFC. However, the All Ordinaries stock index increased again from 2010 followed by a moderate fall in 2011 but by 2019 it was slightly higher than its 2007 value. The Art Price index though, continued to fall until a slight increase in 2013 although in 2014 there was another fall followed by only moderate increases and by 2019 it had still not reached its 2007 value.

\footnotetext{
${ }^{25}$ ABS 6416.0 - Residential Property Price Indexes: Eight Capital Cities
} 
Figure 5: Art Price, All Ordinaires and Housing Price Indices

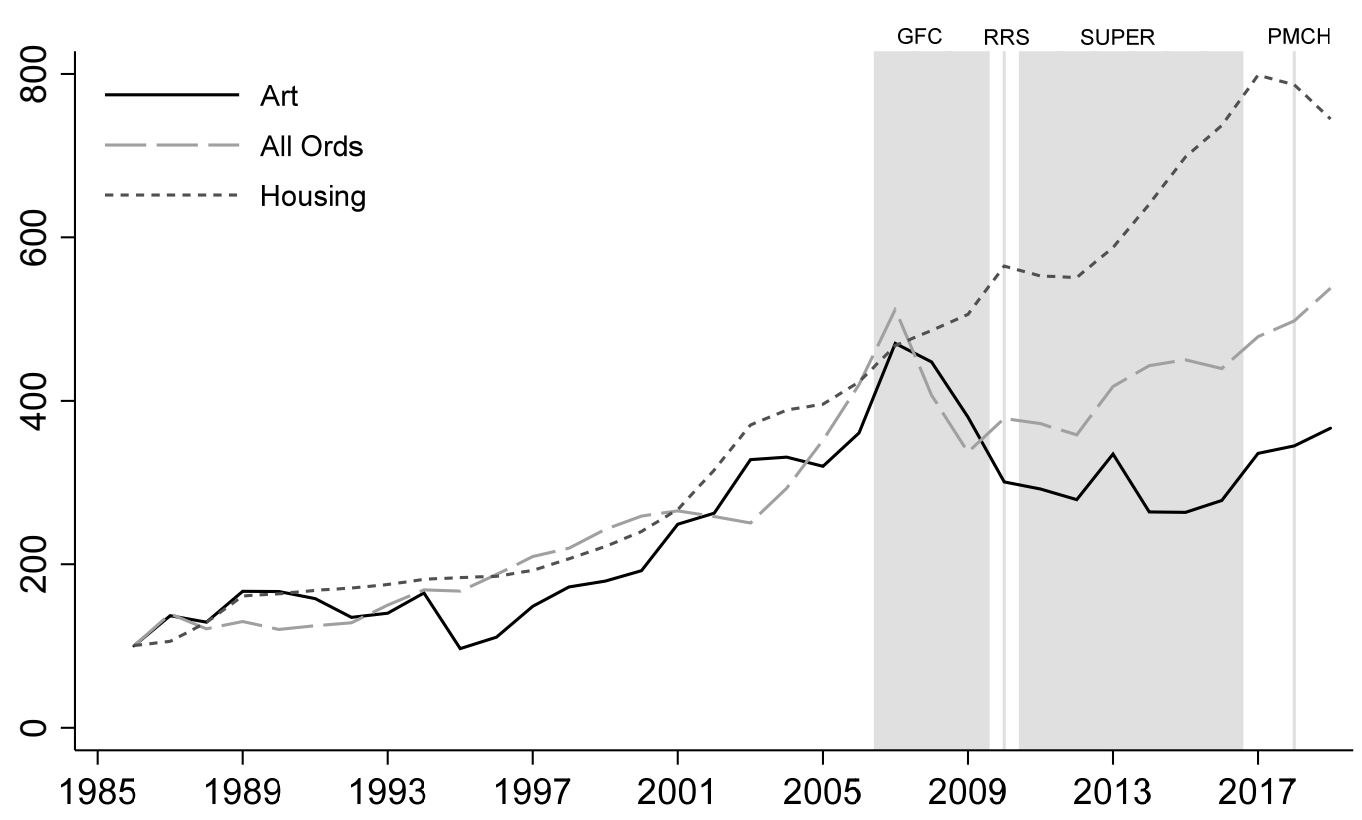

Figure 6 shows a comparison of the annual returns for the three markets. ${ }^{26}$ There was a world art market downturn in the 1990s (Higgs 2012) and in Figure 6 a large fall in returns in the art market occurred in 1995. During the period of the GFC we see falls in both art and All Ordinaires returns. For art returns we also see falls in 2010 and 2014 and we do not see corresponding falls in these time periods for either the All Ordinaries or housing.

Figure 6: Art Price, All Ordinaires and Housing Price Returns

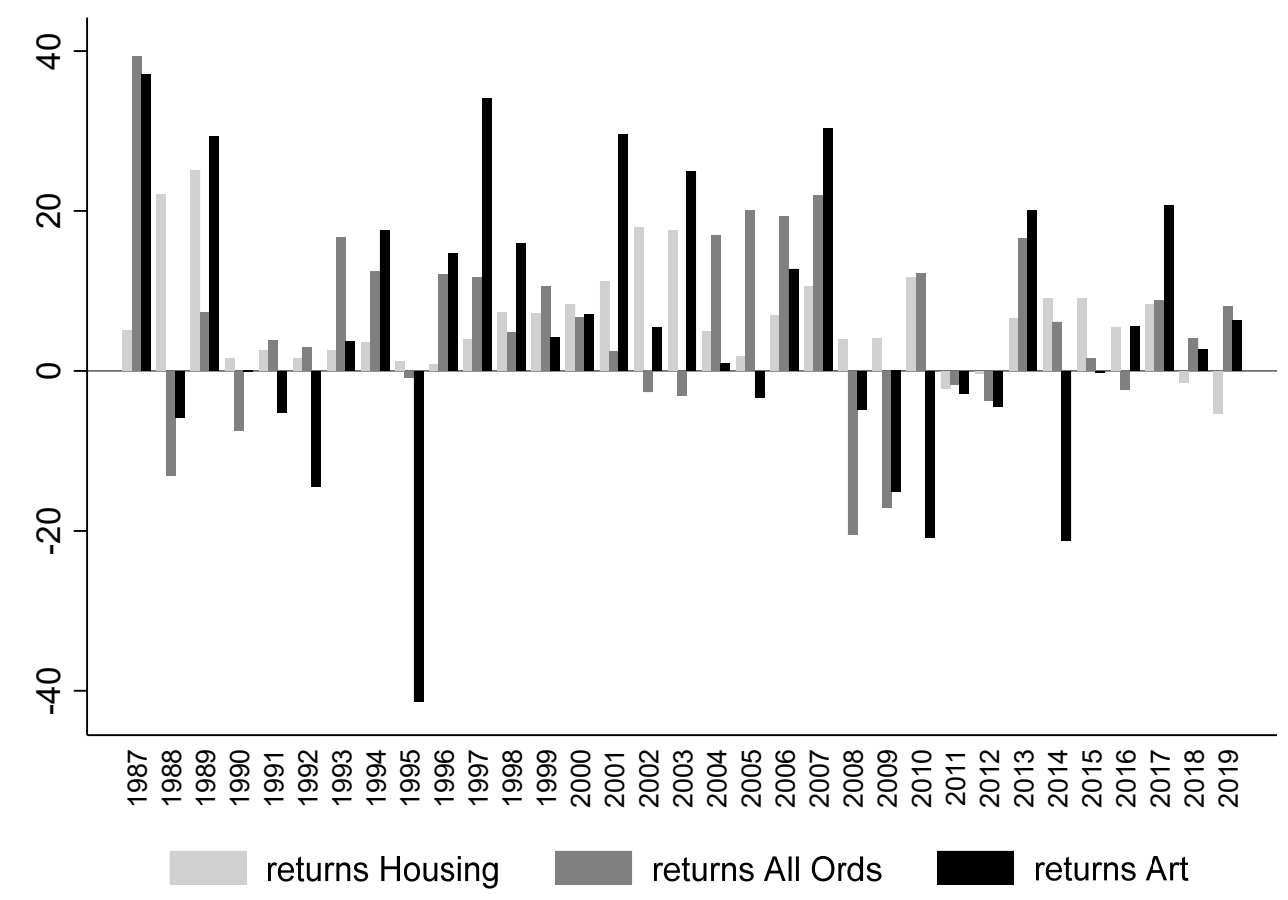

${ }^{26}$ Annual returns are calculated as $100\left[\exp \left(\hat{\rho}_{t}-\hat{\rho}_{t-1}\right)-1\right]$ 


\section{5:2 The Quantile Art Index}

Prices of artworks sold in the sample vary widely from a minimum value of $\$ 11$ to a maximum value of $\$ 2,400,000$. This suggests a possible segmentation in the art market with respect to price. In order to analyze the segments of the market separately we can model the different price quantiles as different segments of the market. This can be done by use of quantile regression (Koenker and Bassett 1978). In the regressions estimated in Section 4 we assumed that we were modelling the conditional mean of the prices. By contrast the quantile regression approach models the conditional quantiles of the prices.

The quantiles of a random variable are parameters of the distribution just as the expected value and the variance are. They are defined as the percentage levels of the variable. The most commonly referred to quantile is the $50 \%$ of the variable. Just as the average of the variable can be used to estimate the expected value $(\mu)$ of the variable as:

$$
\mu=\int_{-\infty}^{\infty} x f(x) d x
$$

where for the random variable $x$ with a probability density defined by $f(x)$. The $50 \%$ quantile $\left(\varphi_{50}\right)$ of the same random variable is defined as the value of $x$ where the probability of all values below it is equal to .50 or $P\left(-\infty<x<\varphi_{50}\right)=.50$ that is defined as:

$$
.50=\int_{-\infty}^{\varphi_{50}} f(x) d x .
$$

Thus $\varphi_{50}$ can be estimated can be estimated via the mid-point (or median) of the observations. ${ }^{27}$ Other quantiles can be defined by different percentages. Thus, for any quantile $q$ (where $0<q<1)$ which is defined as $P\left(-\infty<x<\varphi_{q}\right)=q$ and formally we have:

$$
q=\int_{-\infty}^{\varphi_{q}} f(x) d x
$$

The estimates of $\varphi_{q}$ can be found from the empirical cumulative density of the data by finding the value that corresponds to the $q$ th value of the data. Alternatively, if we sort the observations in ascending order the quantiles can be found by the values of $x$ at each percentage.

\footnotetext{
27 Nomenclature is difficult here since many text book treatments refer to the mid-point value as the median where the $50 \%$ percentile is a parameter of the distribution and not the estimate.
} 
Figure 7 is a plot of the empirical cumulative distribution function of the $\log$ transformation of the prices $\left(\log \left(P_{j t}\right)\right.$ that is used as the dependent variable in $\left.(1)\right)$ except that the axes are reversed. From this plot we can locate the values of the $\log \left(P_{j t}\right)$ that define the various quantiles. From Figure 7 we can read the $q^{\text {th }}$ quantile of the $\log$ prices where $0<q<1, \hat{\varphi}_{10}=5.8, \hat{\varphi}_{25}=6.7, \hat{\varphi}_{50}=8.1, \hat{\varphi}_{75}=9.2$ and $\hat{\varphi}_{90}=10.2$. Which are equivalent to $\$ 330, \$ 812, \$ 3,294$, and $\$ 26,903$ respectively.

\section{Figure 7: Quantiles of the Dependent Variable}

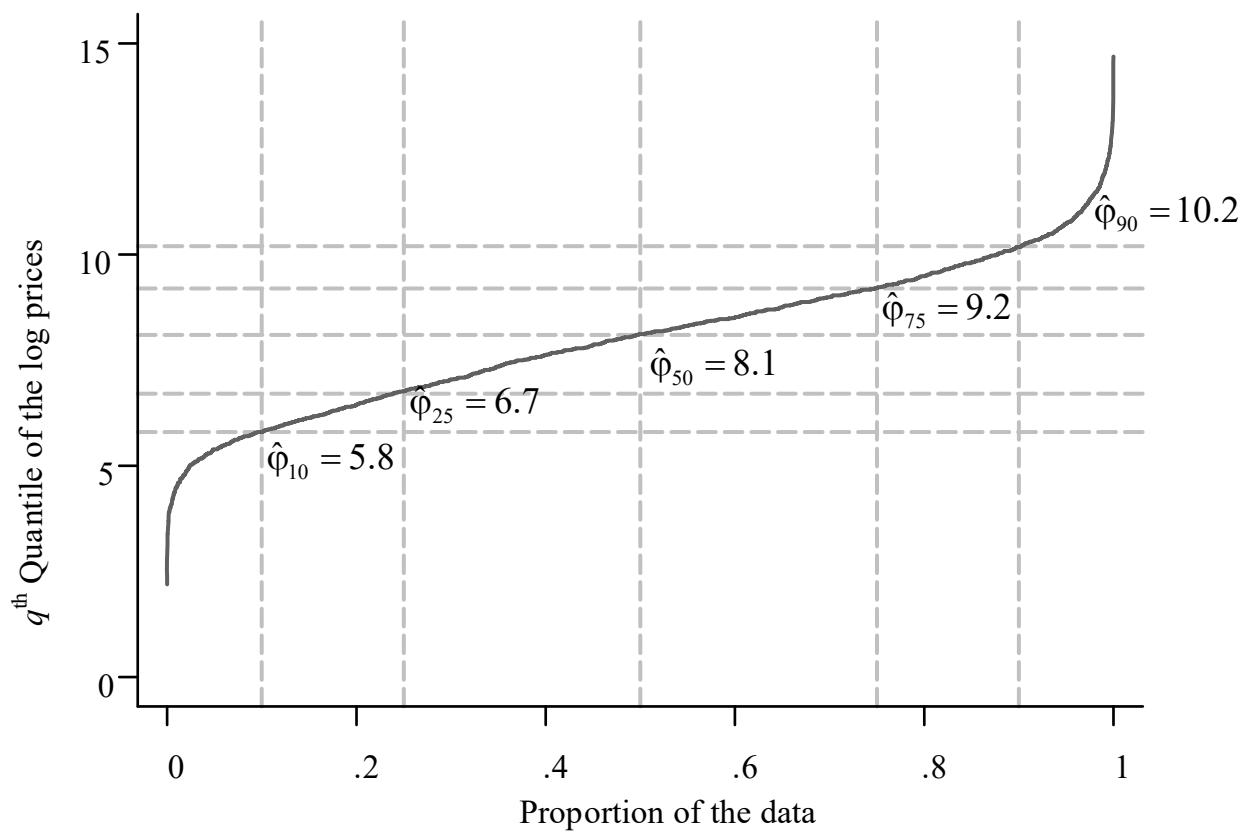

Renneboog and Spaenjers (2013) provide three reasons for the segmentation of the art market. First, art is indivisible so typically small investors are not able to invest in high-end work. Secondly, wealthy individuals may be less likely to buy in the lower end of the market as these works may not necessarily signal the same social status. Thirdly, the more expensive parts of the market may be prone to speculation.

In this section we use quantile regression to examine art characteristics and to develop indices across the price distribution. Quantile regression estimates the conditional $q^{\text {th }}$ quantile of the dependent variable for $0<q<1$. For example, $q=0.5$ (or median) measures the middle value price of artworks given certain characteristics, whereas the 0.1 quantile represents a lower segment and the 0.9 quantile an upper segment. The conditional quantile model for the dependent variable $y_{i}$ given the independent variables $x_{i}$ is given by,

$$
Q_{y_{i}}\left(q / x_{i}\right)=x_{i}^{\prime} \alpha^{q}
$$


where, $y_{i}=\log \left(P_{j t}\right)$ and $x_{i}^{\prime} \alpha^{q}=\alpha+\sum_{t=2}^{T} \rho_{t} D_{t}+\sum_{n=2}^{N} \beta_{n} A_{n}+\sum_{k=1}^{m} \alpha_{k} X_{j k t}$. The coefficients of the $q^{\text {th }}$ quantile of the conditional distribution are defined as a solution to the minimization problem (Koenker and Bassett 1978)

$$
\min _{\alpha \in \mathfrak{R}} \sum_{i: y_{i} \geq x_{i}^{\prime} \alpha} q\left|y_{i}-x_{i}^{\prime} \alpha^{q}\right|+\sum_{i: y_{i}<x_{i}^{\prime} \alpha}(1-q)\left|y_{i}-x_{i}^{\prime} \alpha^{q}\right|
$$

Although the optimization defined by (6) does not have an explicit solution we can find a solution when (6) is posed as a linear programming problem. The estimation results and pseudo- $R^{2}$ for five different quantiles, $q=0.1,0.25,0.5,0.75$ and 0.9 are shown in Table 2. ${ }^{28}$ Standard errors for the quantile regression are obtained using the $X Y$-pair bootstrap method with 100 replications. Also shown in this Table are the F-tests for the joint significance on the coefficients of the year dummy variables, the dummy variables for month, the auction house dummy variables and the artists fixed effects. The F-tests are all significant for all quantiles. Table 3 reports Wald-tests on the equality of slope parameters (that the parameters estimated for the different quantiles are equal) for two quantile comparisons $(0.1,0.5)$ and $(0.5,0.9)$.

The quantile regression results indicate that artwork at varying price levels is influenced in different ways by their characteristics. Although the quadratic term on the surface area $\left(s q a^{2}\right)$ is not significant for any of the quantiles, the linear term is significant for each quantile and increasing with higher quantiles. The slope equality test on the linear term (sqa) can be rejected for both quantile pairs $(0.1,0.5)$ and $(0.5,0.9)$ this implies that the size of the artwork influences the price to a greater and greater extent for art in the different price segments.

In the case of the different mediums we get differences between price segments for wood but not bark or paper. The estimated coefficients for the onwood characteristic are positive and significant and increase in magnitude across all the quantiles although a slope equality test can only be rejected for the $(0.1,0.5)$ pair. However, for both onbark and onpaper, a slope equality test cannot be rejected at either of the quantile pairs $(0.1,0.5)$ and $(0.5,0.9)$.

In the case of the mediums, the estimated coefficients for acrylic, earth, mixed, natural, ochre, oil, polymer and synthetic are positive and significant for all quantiles although the estimated coefficients consistently decrease in magnitude with higher quantiles.

${ }^{28}$ The pseudo- $R^{2}$ is calculated according to Koenker and Machado (1999). 
Further, the slope equality test can be rejected for both quantile pairs $(0.1,0.5)$ and $(0.5,0.9)$ except for mixed where neither can be rejected.

The pattern for the estimated coefficients on gouache, pencil and water follow a similar pattern to the other mediums. However, the estimated coefficients are only significant for the lower quantiles. The slope equality test is rejected for both quantile pairs $(0.1,0.5)$ and $(0.5,0.9)$ for gouache but only for the $(0.1,0.5)$ pair for pencil and water.

The estimated coefficients for etching and linocut are negative and decreasing in value with higher quantiles. Further, they are only significant for the higher quantiles although for etching the slope equality test can be rejected for both quantile pairs $(0.1,0.5)$ and $(0.5,0.9)$ whereas it can only be rejected for the $(0.5,0.9)$ pair for linocut.

For screenprint the estimated coefficients are also negative and decreasing in value with higher quantiles and are significant for all quantiles except the 0.1 quantile. A slope equality test is rejected for both quantile pairs $(0.1,0.5)$ and $(0.5,0.9)$. The slope equality tests cannot be rejected at either of the quantile pairs $(0.1,0.5)$ and $(0.5,0.9)$ for repeat, yd, overseas and for all of the awards variables (Tel80, Tel90, Tel00 and Tel10).

We observe some heterogeneity across the quantiles for auction houses, particularly among the higher quantiles. Individual slope equality tests can be rejected for $95 \%$ of the coefficients on auction houses between the 0.5 and 0.9 quantiles whereas only $10 \%$ can be rejected between the 0.1 and 0.5 quantiles. ${ }^{29}$ Figure 1 highlights the heterogeneity in the prices each artist received for their artwork. This can also be seen in the results of the individual slope equality tests on the coefficients for the artists fixed effects as $60 \%$ can be rejected between the $(0.5,0.9)$ quantiles and $40 \%$ between the $(0.1,0.5)$ quantiles. However, no individual slope equality tests can be rejected for any of the coefficients on the month dummy variables between either the $(0.1,0.5)$ quantiles and the $(0.5,0.9)$ quantiles.

\footnotetext{
${ }^{29}$ For auction houses, artist, months and years the percentages of the slope equality tests that could be rejected were based on 1, 5 and $10 \%$ levels of significance.
} 
Table 2: Quantile Regression Results

\begin{tabular}{|c|c|c|c|c|c|c|c|c|c|c|c|}
\hline Variable & $Q 0.1$ & $Q 0.25$ & $Q 0.5$ & $Q 0.75$ & $Q 0.9$ & Variable & Q0.1 & $Q 0.25$ & $Q 0.5$ & $Q 0.75$ & Q0.9 \\
\hline$C$ & $5.43 * * *$ & $5.978 * * *$ & $6.493 * * *$ & $7.485 * * *$ & $9.329 * * *$ & Synthetic & $1.825 * * *$ & $1.486 * * *$ & $1.24 * * *$ & $0.808 * * *$ & $0.637 * * *$ \\
\hline$Y D$ & 0.042 & $0.071 * *$ & $0.091 * * *$ & $0.068 * *$ & 0.055 & Water & $1.677 * * *$ & $1.078 * * *$ & $0.586 * * *$ & 0.194 & 0.285 \\
\hline sqa & $0.034 * *$ & $0.045 * * *$ & $0.053 * * *$ & $0.060 * * *$ & $0.063 * * *$ & Overseas & 0.225 & 0.144 & $0.41 * *$ & $0.602 * * *$ & $0.607 * * *$ \\
\hline$s q a^{2}$ & -0.000 & -0.000 & -0.000 & -0.000 & -0.000 & Tel80 & $-2.51 * * *$ & $-2.33 * * *$ & $-2.21 * * *$ & $-2.21 * * *$ & $-2.33 * * *$ \\
\hline Onwood & $0.350 * * *$ & $0.485 * * *$ & $0.838 * * *$ & $0.986 * * *$ & $0.912 * * *$ & Tel90 & 0.028 & 0.117 & -0.07 & 0.092 & $0.272 *$ \\
\hline Onbark & -0.067 & 0.049 & $0.143^{*}$ & $0.258 * * *$ & 0.219 & Tel00 & 0.099 & 0.094 & $0.287 * * *$ & $0.272 * * *$ & $0.31 * * *$ \\
\hline Onpaper & $-0.170 * * *$ & $-0.205 * * *$ & $-0.143 * * *$ & $-0.151 * * *$ & $-0.108 * *$ & Tel10 & 0.229 & $0.161 * * *$ & $0.08 *$ & $0.098^{*}$ & 0.018 \\
\hline Acrylic & $1.326 * * *$ & $0.961 * * *$ & $0.796 * * *$ & $0.392 * * *$ & $0.289 * * *$ & Repeat & -0.048 & 0.004 & 0.003 & -0.05 & 0.006 \\
\hline Earth & $1.718 * * *$ & $1.335 * * *$ & $1.311 * * *$ & $0.846^{* * *}$ & $0.758 * * *$ & Fixed Effects & & & & & \\
\hline Etching & 0.164 & -0.252 & $-0.424 * * *$ & $-0.724 * * *$ & $-0.987 * * *$ & Years & Yes & Yes & Yes & Yes & Yes \\
\hline Linocut & 0.21 & -0.469 & $-0.593 *$ & $-0.935 * * *$ & $-1.388 * * *$ & Months & Yes & Yes & Yes & Yes & Yes \\
\hline Mixed & $1.019 * * *$ & $0.921 * *$ & $0.901 * * *$ & $0.649 * * *$ & $0.701 * * *$ & Auction houses & Yes & Yes & Yes & Yes & Yes \\
\hline Natural & $1.664 * * *$ & $1.369 * * *$ & $1.280 * * *$ & $0.820 * * *$ & $0.635 * * *$ & Artists & Yes & Yes & Yes & Yes & Yes \\
\hline Ochre & $1.596 * * *$ & $1.187 * * *$ & $1.178 * * *$ & $0.79 * * *$ & $0.919 * * *$ & & & & & & \\
\hline Oil & $1.217 * * *$ & $0.921 * * *$ & $0.807 * * *$ & $0.518 * * *$ & $0.359 * * *$ & Observations & 15,845 & 15,845 & 15,845 & 15,845 & 15,845 \\
\hline Pen & 0.499 & -0.75 & -0.675 & $-1.454^{*}$ & 0.066 & Pseudo $\bar{R}^{2}$ & 0.491 & 0.544 & 0.561 & 0.562 & 0.556 \\
\hline Pencil & $0.929 * *$ & $0.599 *$ & 0.056 & 0.092 & -0.15 & $F$ tests (years) & $38.97 * * *$ & $56.19 * * *$ & $45.22 * * *$ & $30.49 * * *$ & $23.68 * * *$ \\
\hline Polymer & $1.792 * * *$ & $1.206 * * *$ & $0.998 * * *$ & $0.502 * * *$ & 0.222 & $F$ tests (months) & $2.75 * * *$ & $7.04 * * *$ & $5.71 * * *$ & $4.67 * * *$ & $3.69 * * *$ \\
\hline Gouache & $1.278 * * *$ & $0.873 * * *$ & $0.581 * * *$ & 0.1 & 0.022 & $F$ tests (auction houses) & $19.93 * * *$ & $41.24 * * *$ & $62.19 * * *$ & $35.80 * * *$ & $34.71 * * *$ \\
\hline Screenprint & -0.212 & $-0.578 * * *$ & $-0.72 * * *$ & $-1.092 * * *$ & $-1.297 * * *$ & $F$ tests (artists) & $32.69 * * *$ & $62.55 * * *$ & $70.38 * * *$ & $96.67 * * *$ & $34.48 * * *$ \\
\hline
\end{tabular}

Notes: Dependent variable: logarithm of the sale price. The $\bar{R}^{2}$ is Pseudo $\bar{R}^{2}$ calculated according to Koenker and Machado (1999).

Significance levels: $* * * p<0.01, * * p<0.05, * p<0.1$ based on standard errors obtained using the XY-pair bootstrap method with 100 replications. 
Table 3: Slope Equality Tests for two quantile pairs $(0.1,0.5)$ and $(0.5,0.9)$.

\begin{tabular}{|c|c|c|c|c|c|}
\hline Variable & $(0.1,0.5)$ & $(0.5,0.9)$ & Variable & $(0.1,0.5)$ & $(0.5,0.9)$ \\
\hline$Y D$ & 0.307 & 0.416 & Gouache & 0.008 & 0.009 \\
\hline$s q a^{*}$ & 0.034 & 0.000 & Screenprint & 0.006 & 0 \\
\hline Onwood & 0.000 & 0.520 & Synthetic & 0 & 0 \\
\hline Onbark & 0.144 & 0.574 & Water & 0 & 0.269 \\
\hline Onpaper & 0.624 & 0.512 & Overseas & 0.424 & 0.253 \\
\hline Acrylic & 0.001 & 0.000 & Tel80 & 0.239 & 0.637 \\
\hline Earth & 0.045 & 0.002 & Tel90 & 0.839 & 0.100 \\
\hline Etching & 0.019 & 0.001 & Tel00 & 0.116 & 0.829 \\
\hline Linocut & 0.298 & 0.025 & Tel10 & 0.409 & 0.488 \\
\hline Mixed & 0.785 & 0.555 & Repeat & 0.446 & 0.964 \\
\hline Natural & 0.017 & 0.000 & Years* & 0 & 0 \\
\hline Ochre & 0.022 & 0.085 & Months* & 0.817 & 0.165 \\
\hline Oil & 0.035 & 0.002 & Auction houses* & 0 & 0 \\
\hline Pen & 0.721 & 0.390 & Artists* & 0 & 0 \\
\hline Pencil & 0.062 & 0.675 & & & \\
\hline
\end{tabular}

Notes: These are the Koenker and Bassett (1982) test for the equality of the slope coefficients across quantiles. $p$-values reported. ${ }^{*}$ These are the joint tests reported..$^{30}$

The estimated coefficients on the year dummy variables consistently fall between the 0.1 and 0.5 quantiles whereas there is no consistent pattern between the higher-level quantiles. Further, at the lower quantiles $91 \%$ of the individual slope equality tests on each of the year dummy coefficients between the $(0.1,0.5)$ quantiles can be rejected but none can be rejected between the $(0.5,0.9)$ quantiles.

Figure 8 provides plots of the estimated coefficients and their confidence intervals for the different mediums based on a comparison of the OLS and LAV (50\% quantile). These comparisons are less formal than the tests reported in Table 3 however they provide a visual representation of these types of comparisons. From this plot we note there are no coefficients were both are significant but that differ in their sign. Except for the Gouache medium in all other cases the estimated coefficients for each medium have equivalent coefficients. Because the LAV estimates are more robust to outliers for the dependent variable they tend to be of smaller magnitude than the OLS values.

30 The individual values of these parameter estimates are plotted in the appendix. 


\section{Estimates.}

Figure 8 Coefficient plot of the Medium Characteristics for the LAV and OLS

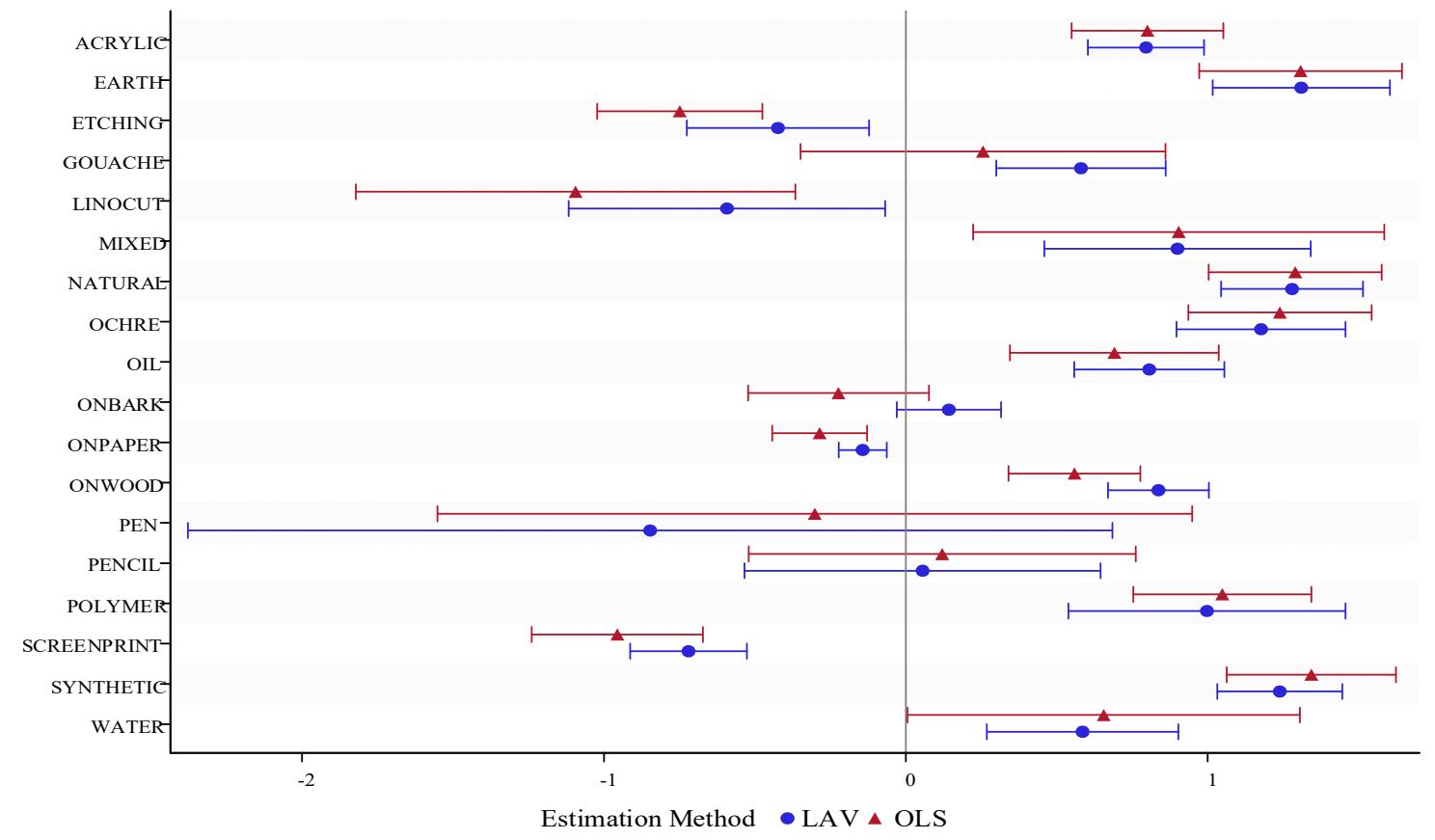

Figure 9 is the equivalent to Figure 8 except where the comparison of coefficient estimates is between the $10 \%$ and $90 \%$ quantiles. In this case we note that the contributions of most of the medium characteristics generally have a greater influence on the sale price in the model of the lower $10 \%$ versus in the $90 \%$ model. However, there are exceptions for the estimated coefficients for those on wood and on paper. This would indicate that works on these mediums tend to be less valuable in the lower tier of the market than the upper tier.

Figure 9 Coefficient Plot of the Medium Characteristics for the 10\% and 90\% Quantile Estimates.

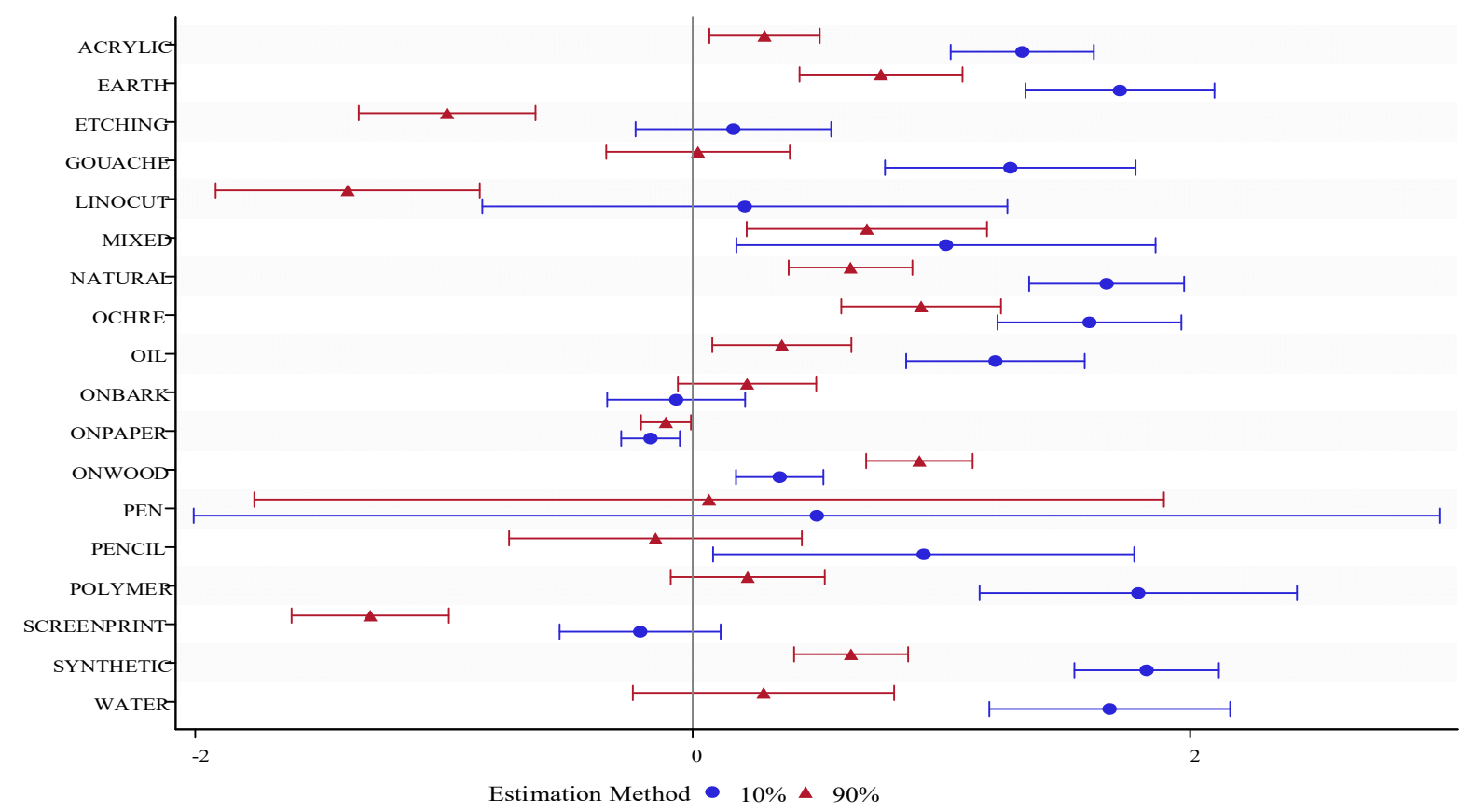


Figure 10 plots the nominal art price index constructed for each of the quantile regressions as well as for OLS. While there is little difference in the profiles of the indices at the higher-level quantiles there is at the lower quantile levels. For the lower-level quantiles the index is higher for every year than the corresponding index at the higher-level quantiles and OLS. Also, in 2011 the lower-level quantile indices seem to be slightly increasing whereas the OLS and higher-level indices are still falling. This finding appears to confirm the negative "masterpiece effect" that has been observed by several researchers in prices paid for contemporary and impressionist work. ${ }^{31}$

Figure 10: Art Price Indices based on OLS and Quantile Estimates

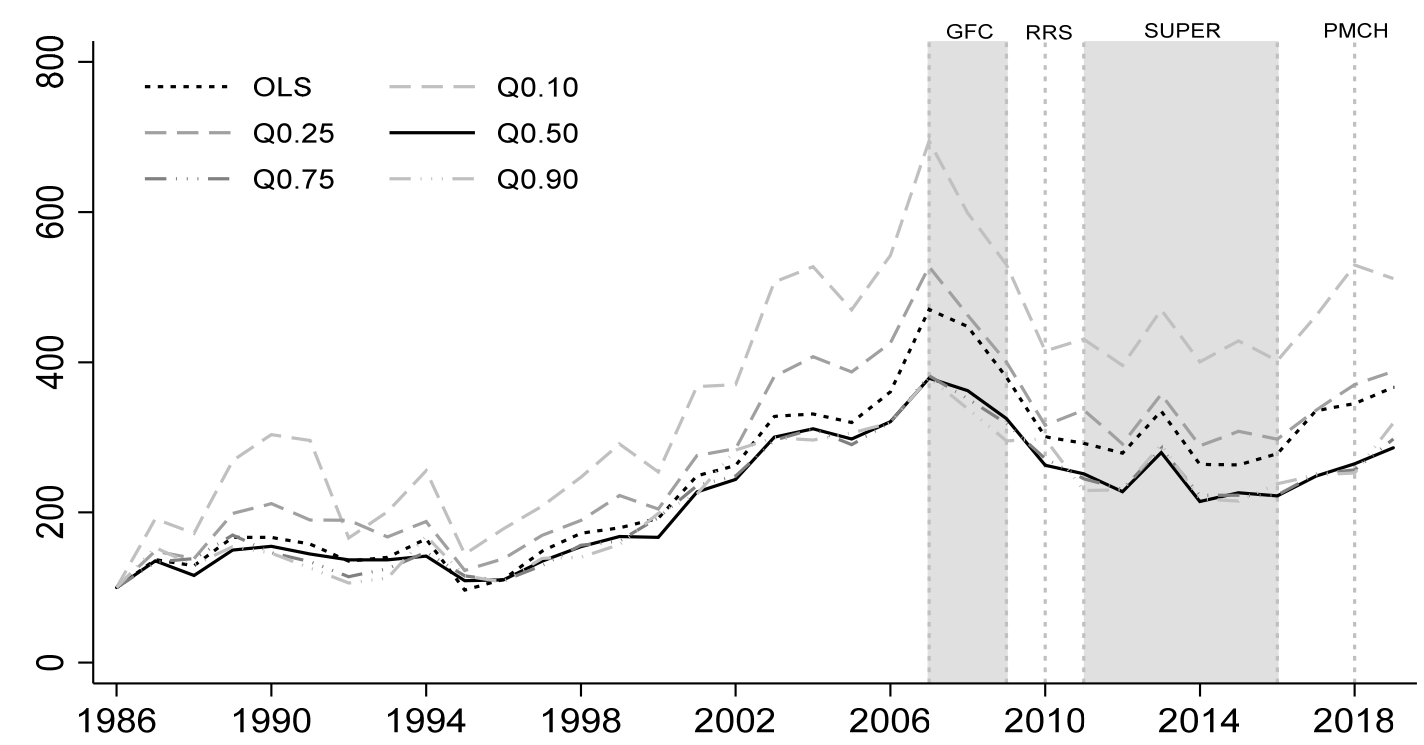

Figure 11 shows a comparison of the annual returns for the $0.1,0.5$ and 0.9 quantiles. During the period of the GFC we see falls in annual returns for all the quantiles. Around the time of the introduction of the Resale Royalty Scheme in 2010 we see falls in the annual returns for the 0.1 and 0.5 quantiles. Corresponding to the introduction of changes to selfmanaged super funds we see a large fall in the annual returns for the 0.9 quantile and a smaller fall for the 0.5 quantile in 2011 and falls in all the annual returns for the $0.1,0.5$ and 0.9 quantiles in 2014.

31 The masterpiece effect proposes that prices of high value works will appreciate faster than lower value works. See the comparison of the results of previous attempts to find this effect in Table 2 in Ashenfelter and Graddy (2003). 
Figure 11: Annual Returns for the 0.1, 0.5 and 0.9 Quantiles.

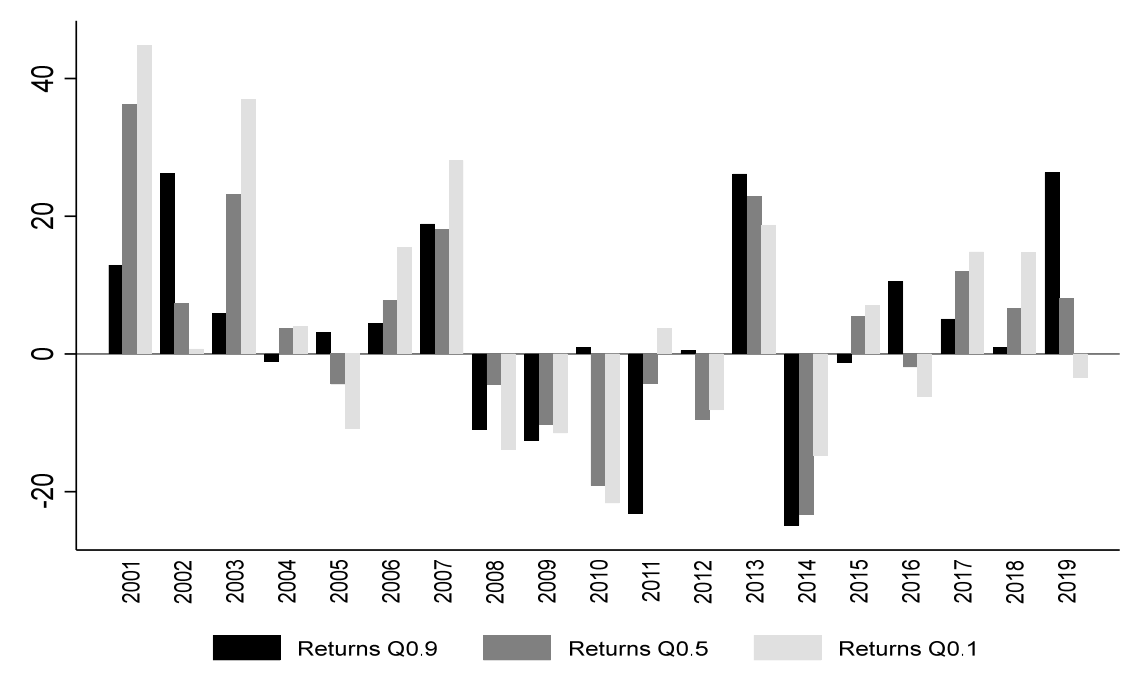

Figure 12 plots the average annual return and risk (as measured by the standard deviation) for OLS and for the $0.1,0.25,0.5,0.75,0.9$ quantiles over the full sample and two sub-samples defined as pre- and post- GFC period. The relationship between risk and return is expected to be positive - the greater the return implies an asset that has greater risk. For the full sample the highest average annual returns were associated with the 0.1 quantile as well as the highest risk. While the average annual return was above $4 \%$ for OLS and the $0.25,0.5,0.75,0.9$ quantiles they all also had higher risk than for the All Ordinaires.

\section{Figure 12: Average Annual Returns and Standard Deviations ${ }^{32}$}
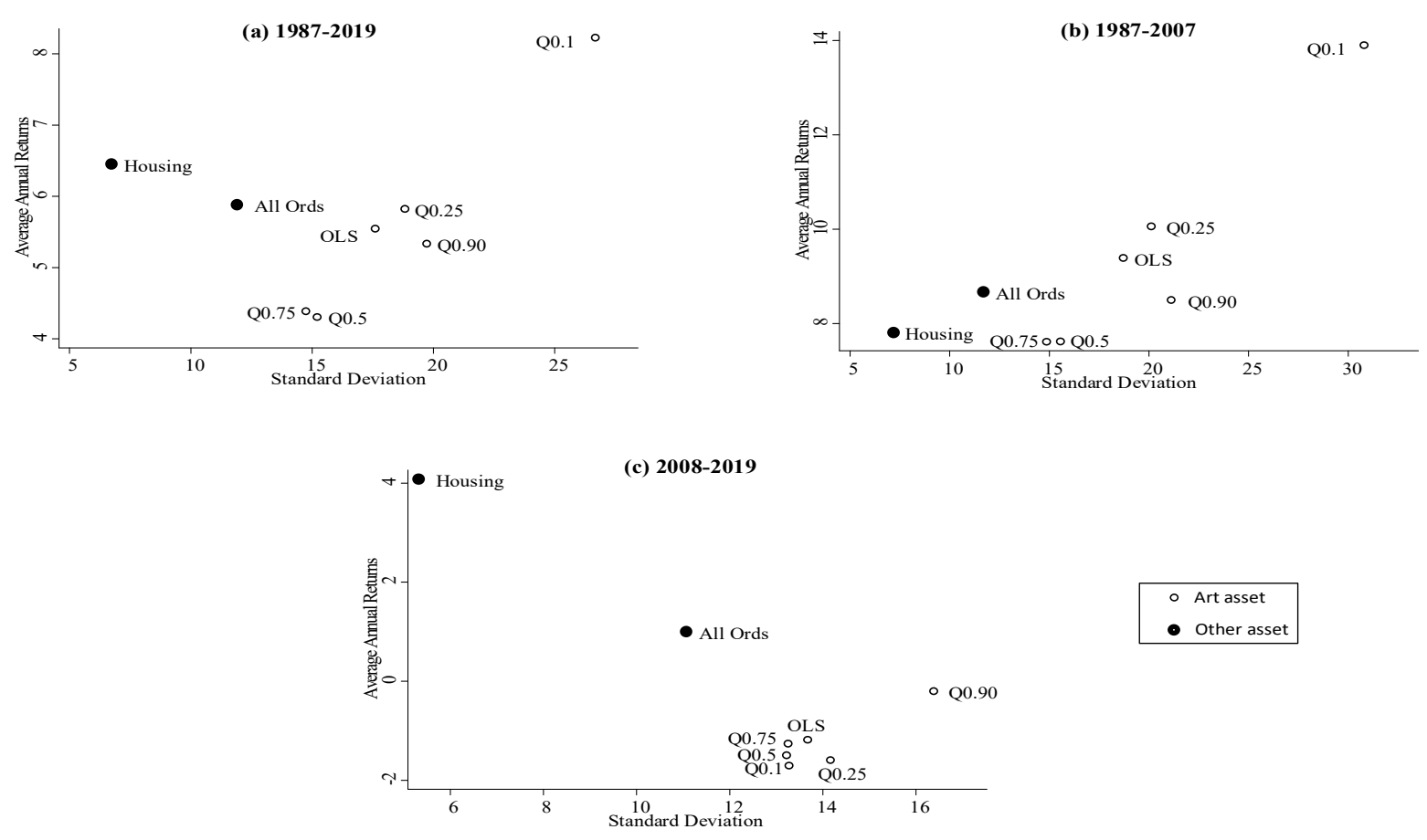

${ }^{32}$ Note that the scale of the vertical axis is not the same in the three plots. 
However, a different pattern emerges when the pre- and post-GFC subsamples are considered. For the pre-GFC subsample each have a similar or higher average annual return than housing as well as a higher risk which matches the idea of higher risk resulting in higher returns for works from all segments of the market. However, for the post-GFC subperiod while all segments of the art market have higher risk than either housing or the All Ordinaries stock index, they also have a negative average annual return. This suggests that the GFC and Government policies since 2008 have had a strong impact on the art market.

In comparison to the global art market we find that while both sales and volumes fell sharply in 2009, there was a strong rebound for the period 2009-2011 following the GFC (Solimano 2019). Etro and Stepanov (2019) develop a global art price index for contemporary artists based on Western art and more than 500 artists using repeated sales. They show that for contemporary art prior to 2007 there was a rapid increase in prices and although there was a substantial decline during the GFC there has subsequently been a sustained increase. Their art price index is illustrated in Figure 13 (solid line) and for comparison the $A A A$ price index is shown based on OLS estimates (dashed line) where both are scaled to start at 100 in 2000 . This highlights a prolonged decrease in price changes for aboriginal art with only a recent slight increase.

Figure 13: Comparison of the estimated mean price index and the global price index for top contemporary western artists.

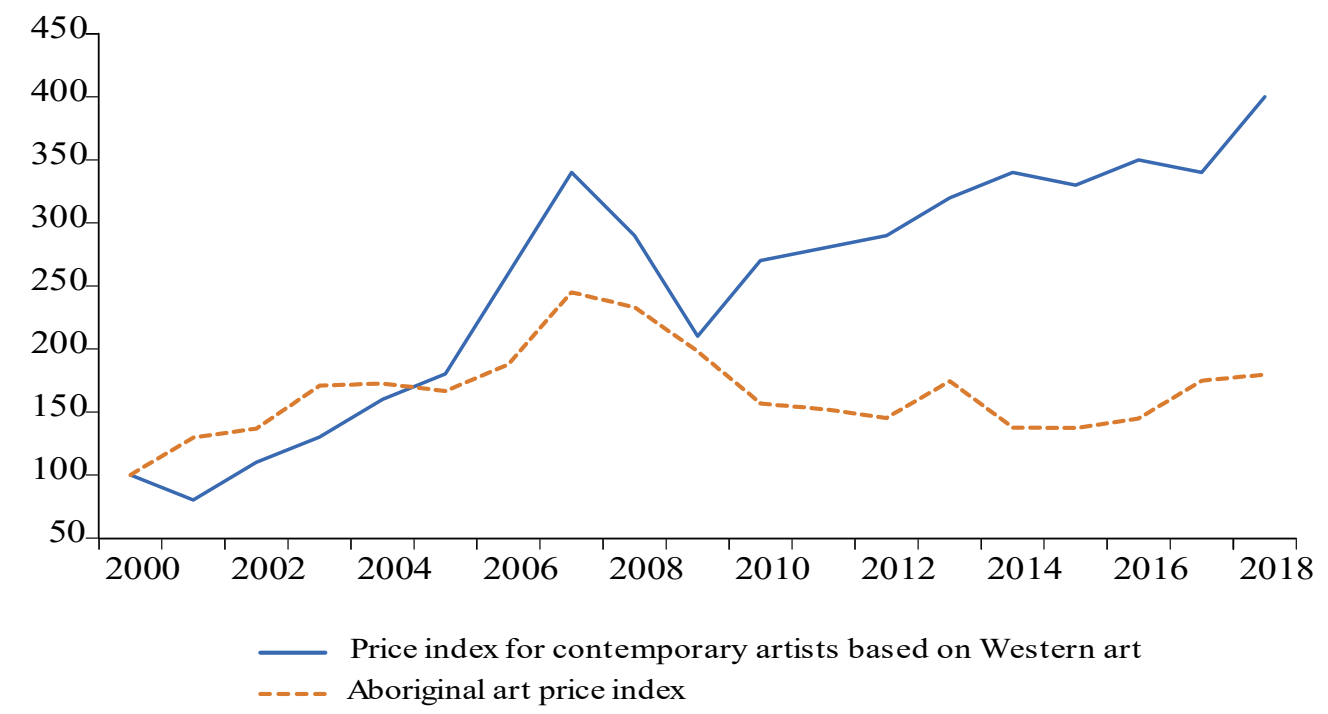

\section{6: Discussion}

In this paper we have estimated the price index for the Australian Aboriginal Art market by collecting the sale price and the characteristics of 15,845 works of art that were sold at auction from 1986 to 2019 by 202 artists. The characteristics of these works were 
determined from the auction catalogues. These include the time sold, the medium of the work, the dimensions of the work, the auction house were sold and the status of the artist. This model allows us to determine how the market for these works changed over time in order to estimate a price index for this period. The variation in value of these artworks over this period is particularly important due to the changes in Australian Federal legislation concerning the status of these artwork as investment assets and the requirement to adhere to the Resale Royalty Act.

We find that the value of these artwork fell after these changes to the investment status of these works and the rates of return for these works as investment assets fell to the point where they became negative for a longer period than art work in other countries after the Global Financial Crisis. Using a quantile regression approach, we were able to subdivide the impacts of these changes by the segment of the market. In doing so we identified significant differences between the impacts of these changes for artwork in the top $10 \%$ of the market from the rest of the market. This approach allowed us to estimate separate price indices for these different aspects of the market.

A caveat to our findings is the inherent limitations in the price data we employ for our analysis. In the 2019 global art market sales of 64.1 billion \$US only 24.2 billion \$US or less than 38\% were estimated to be sold at auction (page 19 McAndrew 2020) with the remainder sold by dealers, at art fairs and on-line. In addition, we have no indication of the number of works that came to auction but did not sell nor do we know the actual transaction for the item since there are usually significant auction costs. Also, when comparing the rates of return of investments, we have not included the significant frictional costs in the market. The 10 to $17.5 \%$ buyer's premium charged the buyer and the $10 \%$ sellers commission would indicate that the price of an artwork would need to rise by up to $27.5 \%$ for a seller to make a profit from the sale.

Recently there is a growing concern that the rapid increase in the value of art sales has been fueled by money laundering activities which has resulted in the imposition of a more

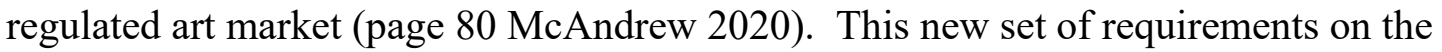
provenance of art and the details of ownership has increased costs for the sellers of art but on the other hand may lead to a more stable market for art. ${ }^{33}$

\footnotetext{
33 Due to the remote locations of some Aboriginal artists, the provenance a few works has been an issue as documented in Chappell and Hufnagel (2014).
} 


\section{References}

Acker, T. (2016), "Somewhere in the world: Aboriginal and Torres Strait Islander art and its place in the global art market", CRC-REP Research Report CR017. Ninti One Limited, Alice Springs.

Ashenfelter, O., K. and Graddy, (2003) "Auctions and the Price of Art", Journal of Economic Literature, 41, 763-786.

Cascone S. (2015), “\$2 Million Aboriginal Art Auction Pays Off for Sotheby’s London”, artnet, June 11.

Challis D. (2019), “The Australian art market has flatlined. What can be done to revive it?", The Conversation, Sept. 27.

Chappell D., S. and Hufnagel (2014), 'Case Studies on Art Fraud: European and Antipodean Perspectives' in Contemporary Perspectives on the Detection, Investigation and Prosecution of Art Crime, Eds. Chappell D and Hufnagel S, Ashgate Publishing Ltd., England, pp. $57-77$.

Chwelos P. (2003), “Approaches to Performance Measurement in Hedonic Analysis: Price Indexes for Laptop Computers in the 1990s", Economics of Innovation and New Technology, 12, 199-224.

Court A. (1939), "Hedonic Price Indexes with Automotive Examples." In: The Dynamics of Automobile Demand, edited by V. von Szeliski, S. Horner, and C. Roos, 99-117. New York: The General Motors Corporation.

Deloitte, ArtTactic, (2019), Art \& Finance Report 2019, https://www2.deloitte.com/content/dam/Deloitte/global/Documents/Finance/gx-fsi-artand-finance-report-2019.pdf

Demir E., Gozgor G. and Sari E. (2018), "Dynamics of the Turkish paintings market: A comprehensive empirical study”, Emerging Markets Review, 36, 180-194.

Etro, F. and E. Stepanova (2019), "On the Efficiency of Art Markets. Evidence of return rates from old masters' paintings to contemporary art." University of Florence, Working Paper 29, September. https://www.disei.unifi.it/upload/sub/pubblicazioni/repec/pdf/wp29_2019.pdf

Fernandez-Cornejo, J. and S. Jans (1995), “Quality-adjusted Price and Quantity Indices for Pesticides.” American Journal of Agricultural Economics, 77, 645-659.

Genocchio, B. (2008), Dollar Dreaming inside the Aboriginal Art World, Hardie Grant Books, Melbourne.

Griliches Z. (1961), "Hedonic Price Indexes for Automobiles: An Econometric Analysis of Quality Change." in The Price Statistics of the Federal Government, General Series No. 73, edited by Price Statistics Review Committee, 137-196. New York: Columbia University Press.

Higgs H. and Worthington A. (2005), "Financial Returns and Price Determinants in the Australian Art Market, 1973-2003”, Economic Record, 81, 113-123.

Higgs H. (2012), "Australian Art Market Prices during the Global Financial Crisis and Two Earlier Decades”, Australian Economic Papers, 51, 189-209. 
Hodgson D. and Seçkin A. (2012), "Dynamic Price Dependence of Canadian and International Art Markets: An Empirical Analysis", Empirical Economics, 43, 867-890.

Koenker R. and Bassett, G. (1978), "Regression Quantiles”, Econometrica, 46(1), 33-50.

Koenker R. and Bassett, G. (1982). "Robust Tests for Heteroskedasticity Based on Regression Quantiles," Econometrica, 50, 43-62.

Koenker R. and Machado J. (1999), "Goodness of Fit and Related Inference Processes for Quantile Regression”, Journal of the American Statistical Association, 94, 1296-1310.

Lamont L. (2011), “Art investors painted into tight corner”, The Sydney Morning Herald, 14 March

Lehman-Schultz C. (2013), "How super laws are killing the market for Indigenous art", The Conversation, Nov. 1, 2013.

Lye J. and J. Hirschberg (2017), "Secondary school fee inflation: an analysis of private high schools in Victoria, Australia", Education Economics, 25, 482-500.

McAndrew, C. (2020), The Art Market 2020, An Art Basel \& UBS Report. https://d2u3kfwd92fzu7.cloudfront.net/The_Art_Market_2020-1.pdf.

Renneboog L. and Spaenjers, C. (2013), "Buying Beauty: On Prices and Returns in the Art Market", Management Science, 59, 36-53.

Renneboog L. and van Houtte T. (2002), "The Monetary Appreciation of Paintings: From Realism to Magritte", Cambridge Journal of Economics, 26, 331-358.

Rosen S. (1974), "Hedonic Prices and Implicit Markets: Product Differentiation in Pure Competition.” Journal of Political Economy, 82, 34-55.

Schwartz A. and B. Scafidi (2004), "What's Happened to the Price of College? Qualityadjusted Net Price Indexes for Four-year Colleges", The Journal of Human Resources, $39,723-745$.

Simpson S (2015), Review of the Protection of movable Cultural Heritage Act 1986, downloaded https://www.arts.gov.au/sites/default/files/borders-of-culture-review-of-theprotection-of-movable-cultural heritage-act-1986-final-report2015.pdf?acsf files redirect $5^{\text {th }}$ June 2020 .

Solimano A. (2019), "The Art Market at Times of Economic Turbulence and High Inequality", downloaded https://institute.eib.org/wp-content/uploads/2019/06/Art-MarketEconomic-Trubulence-Inequality-Paper-Solimano.pdf, 25th Feb 2020.

Taylor D. and L. Coleman (2011), "Price determinants of Aboriginal art, and its role as an alternative asset class", Journal of Banking and Finance, 35, 1519-1529.

Wilson-Anastasios M. (2019), "Health check due on Resale Royalty Scheme as data murky on Indigenous beneficiaries", Oct $3^{\text {rd }}$, The Sydney Morning Herald.

Witkowska D. (2014), “An Application of Hedonic Regression to Evaluate Prices of Polish Paintings", International Advances in Economic Research, 20, 281-293. 


\section{Appendix Estimated Coefficient plots}

Figure A.1 The year indicator variables

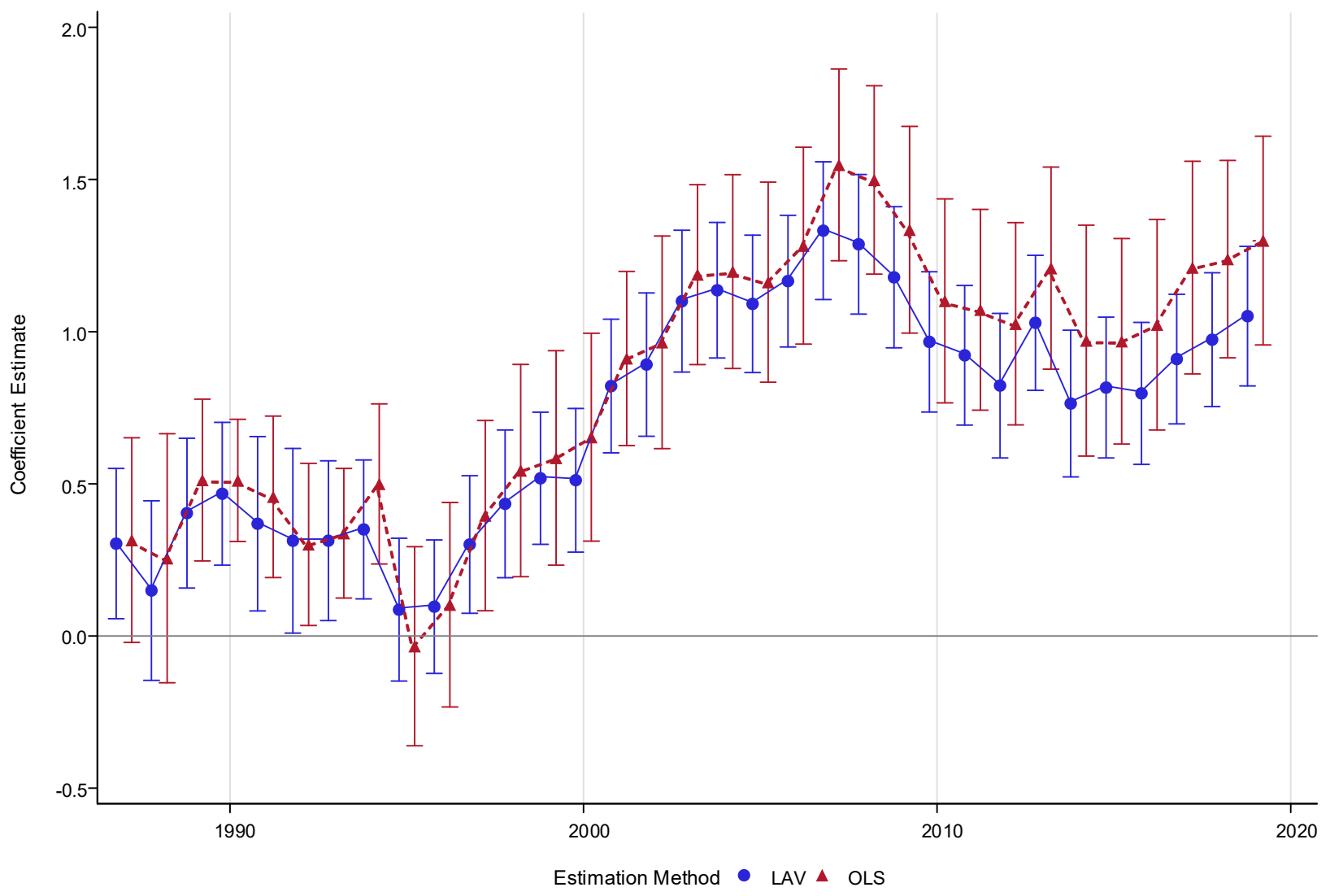




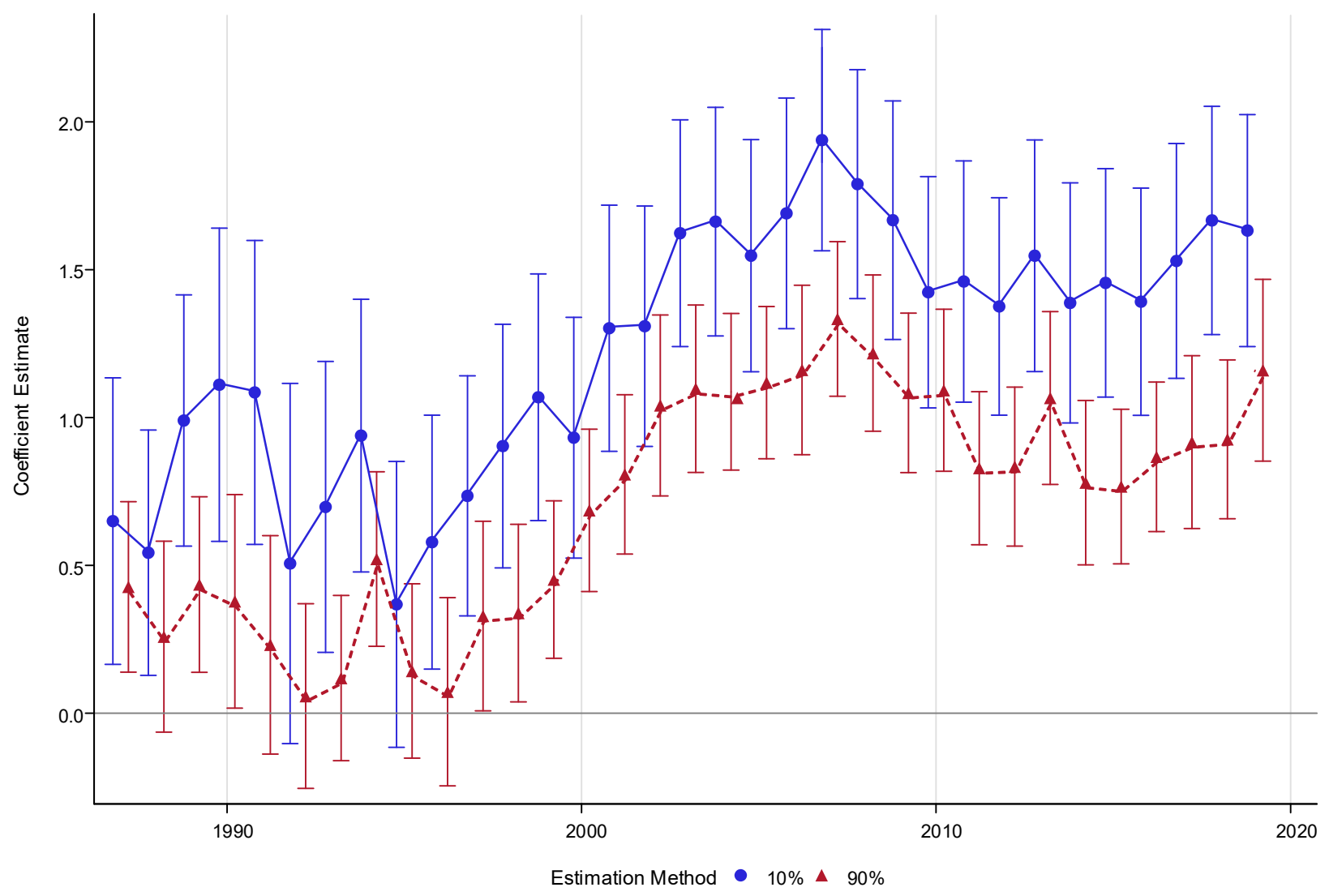




\section{Figure A.2 The Auction House Indicator Variables}

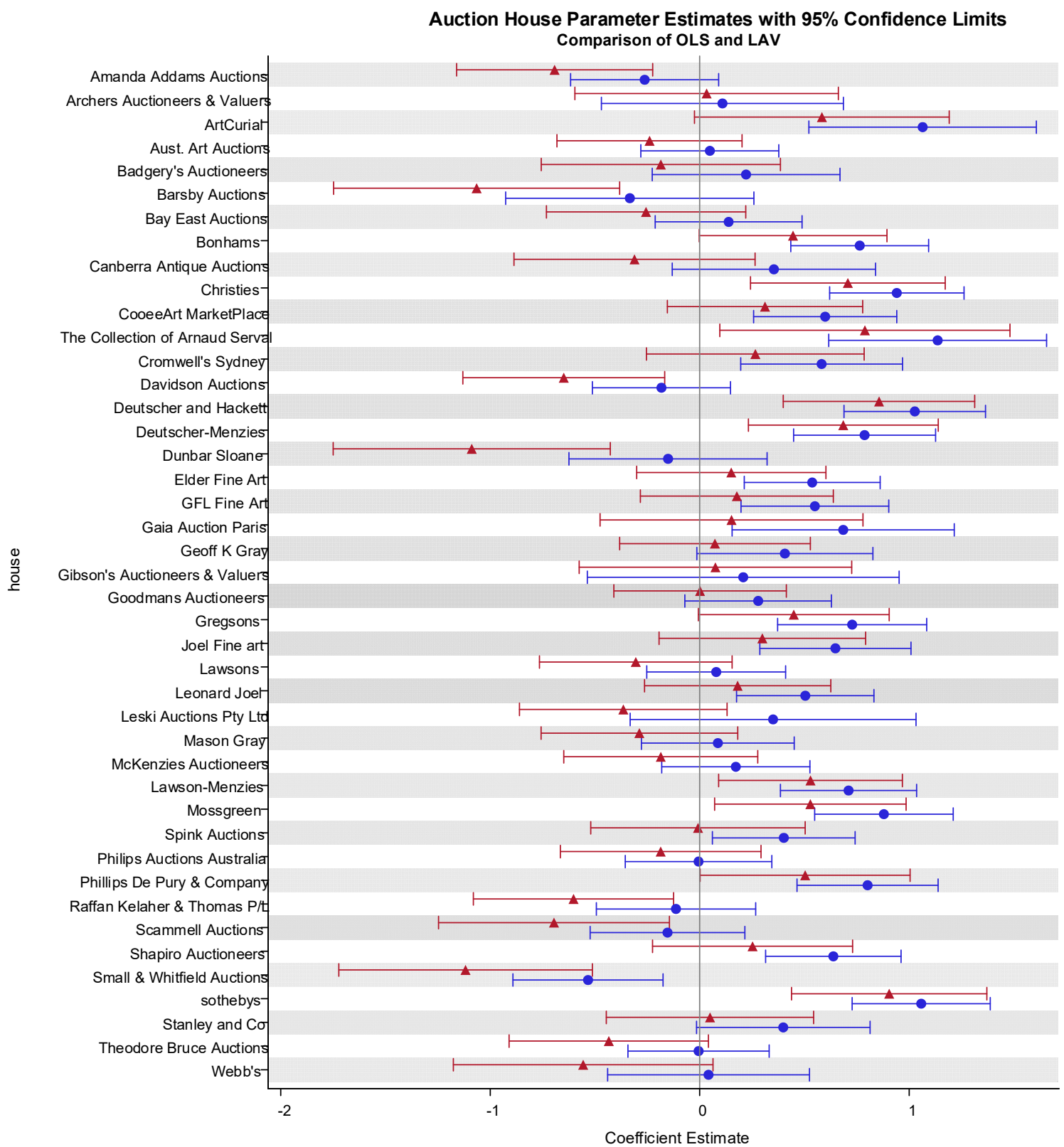

Estimation Method $\bullet$ LAV $\Delta$ OLS 
Auction House Parameter Estimates with 95\% Confidence Limits Comparison of $10 \%$ and $90 \%$

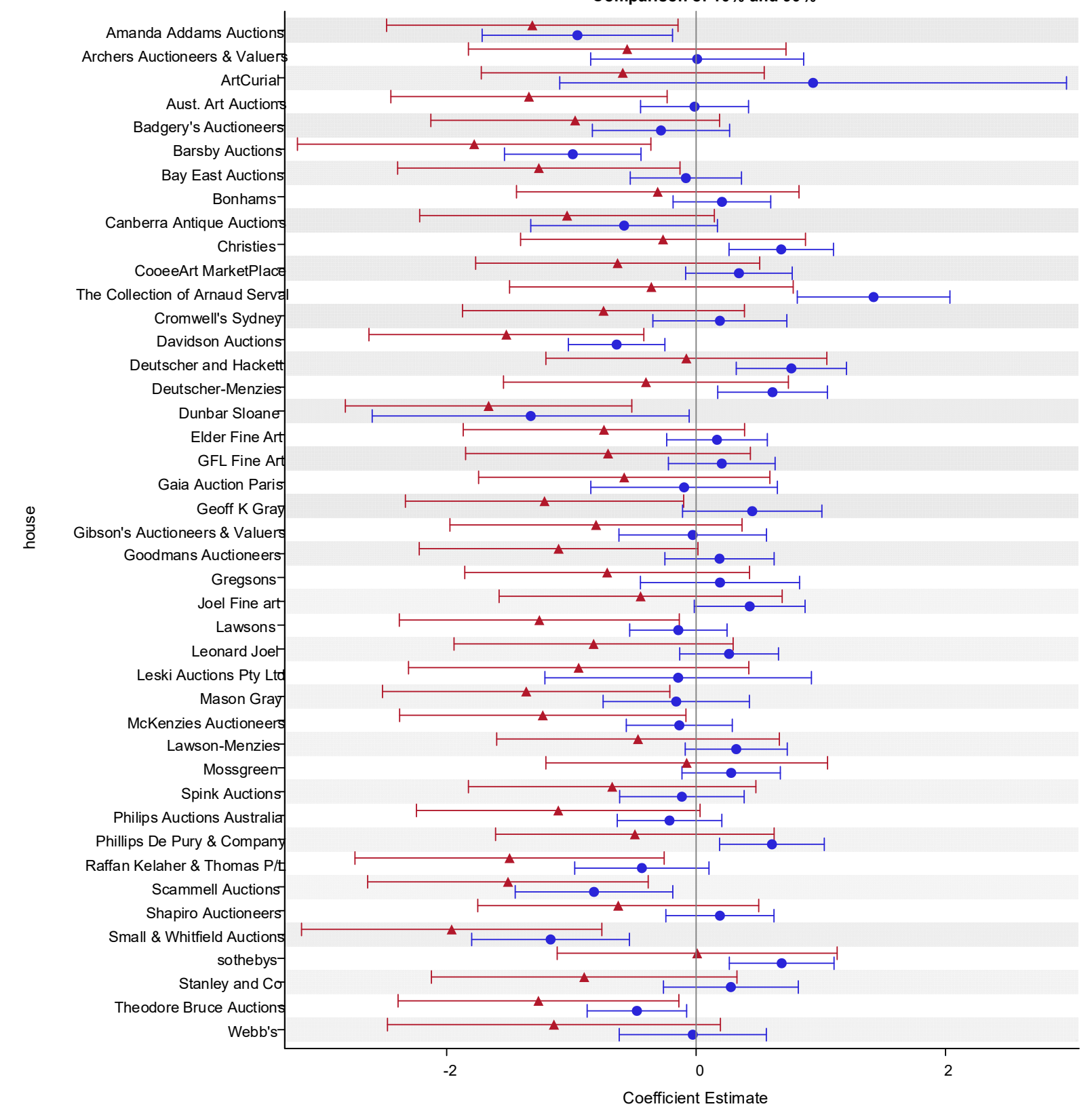

Estimation Method - $10 \%$ \ $90 \%$ 
Figure A.3 The Repeat sales, Sold out of Australia, Sold after death and Telstra Awards Indicator Variables
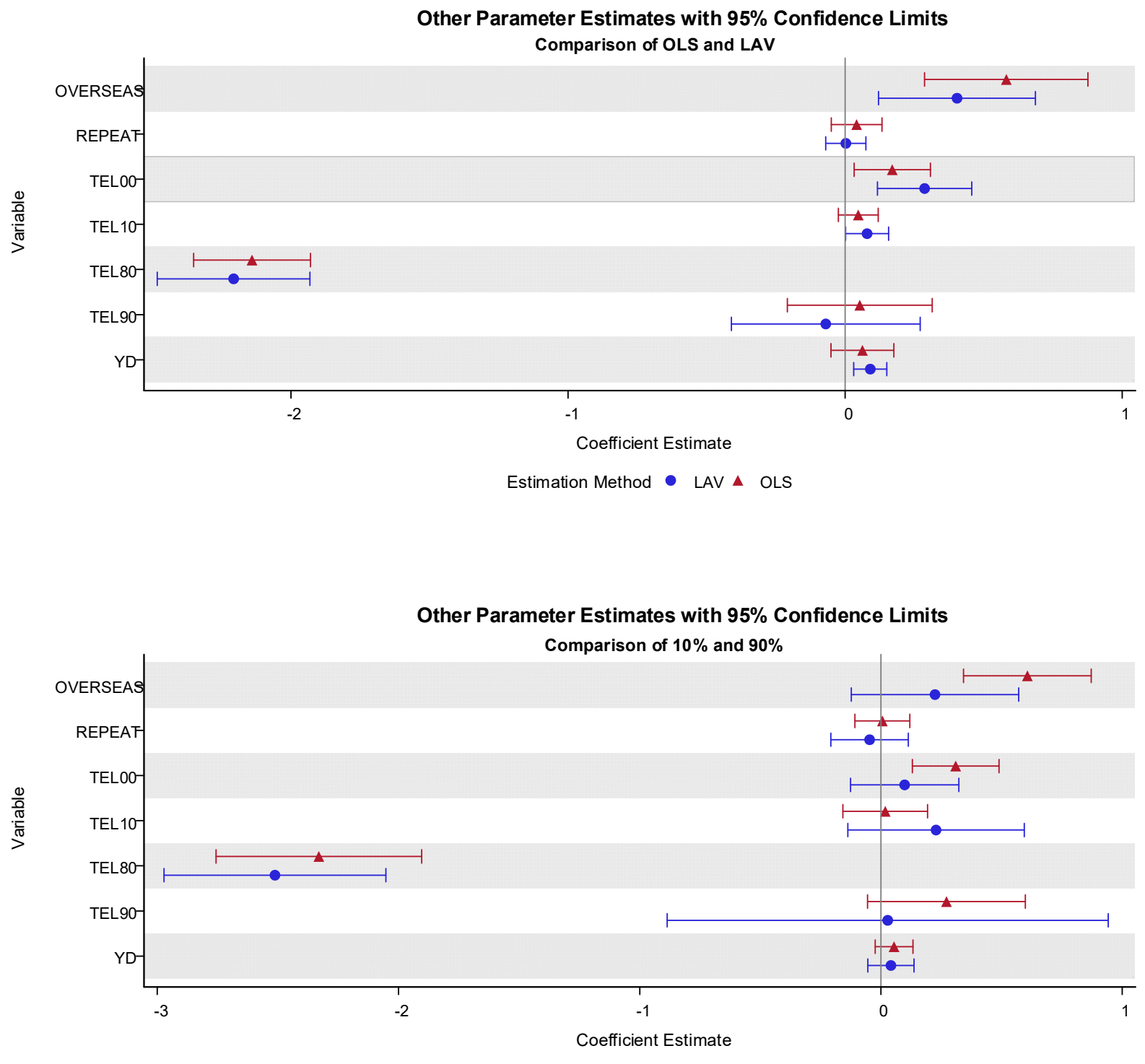

Estimation Method - $10 \%$ \ $90 \%$ 
Figure A.4 The Artist Specific Indicator Variables

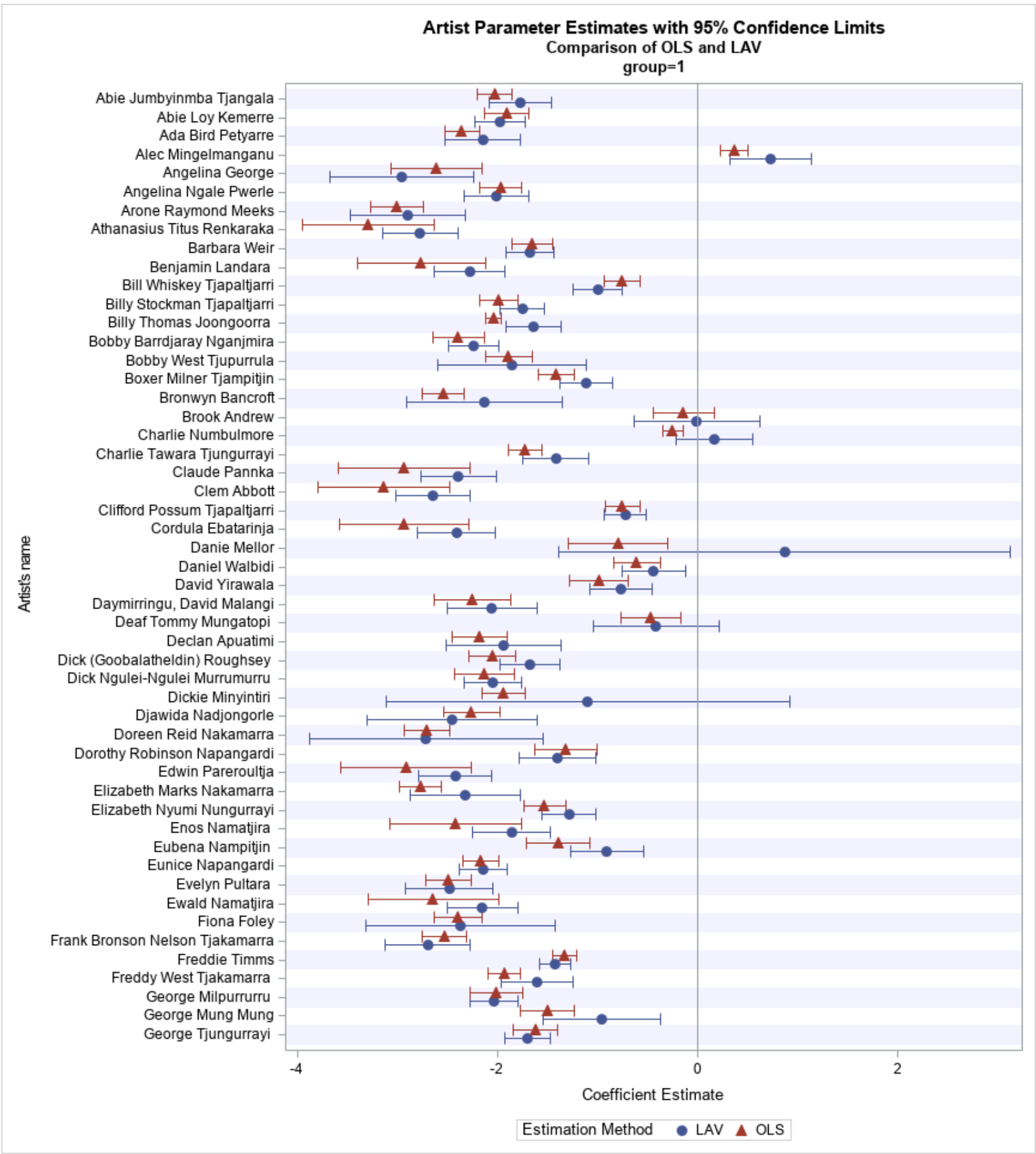




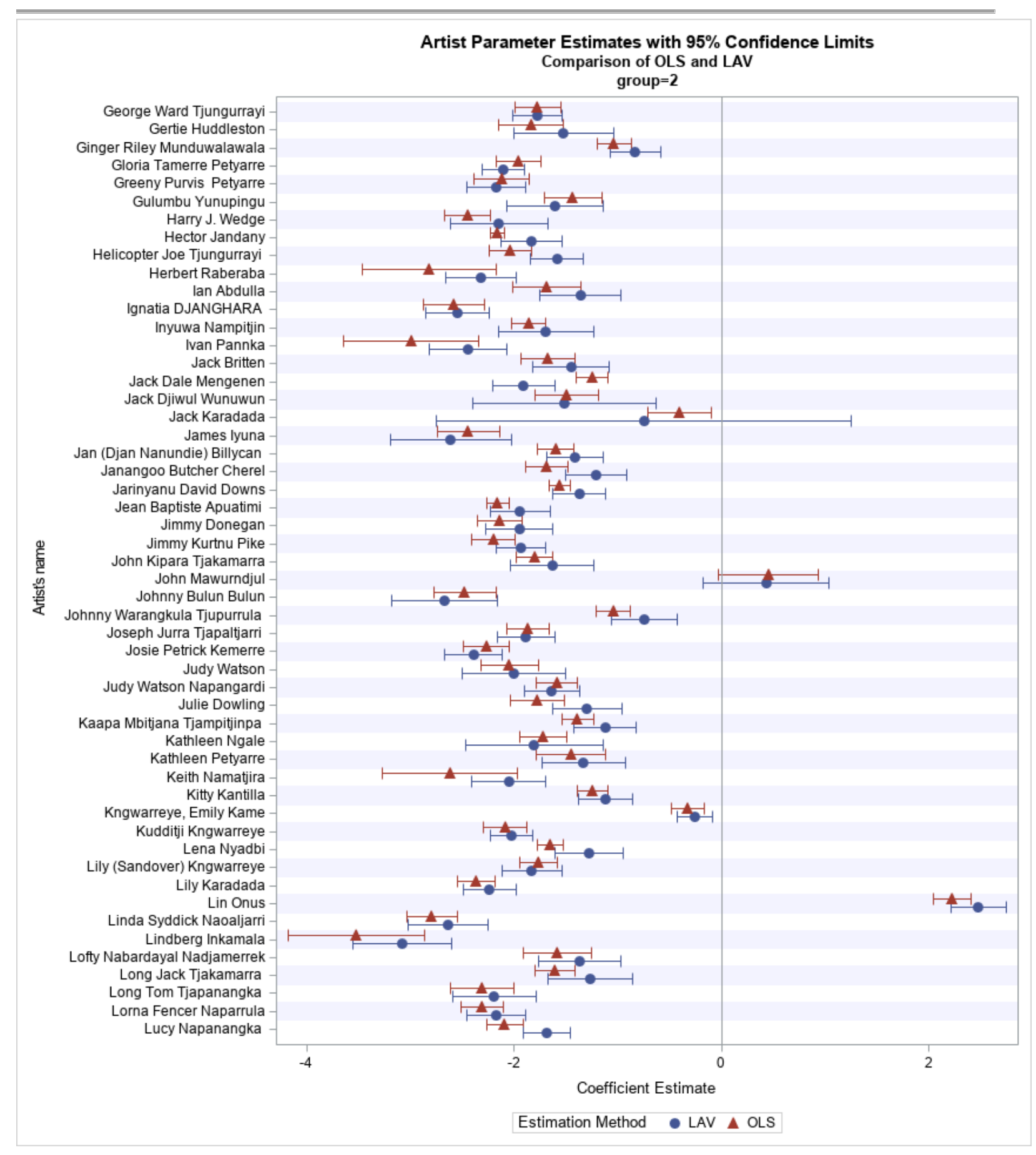




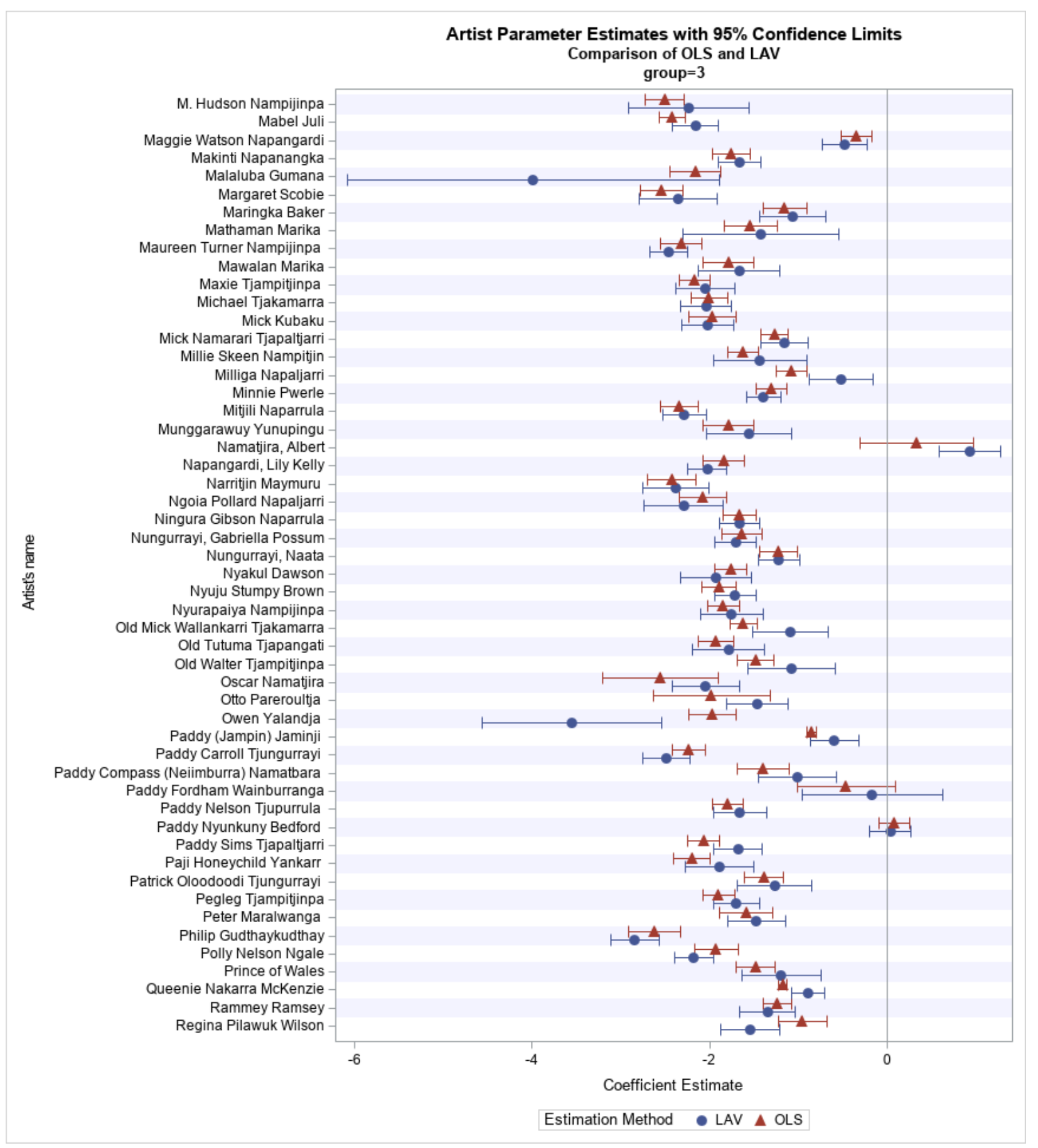




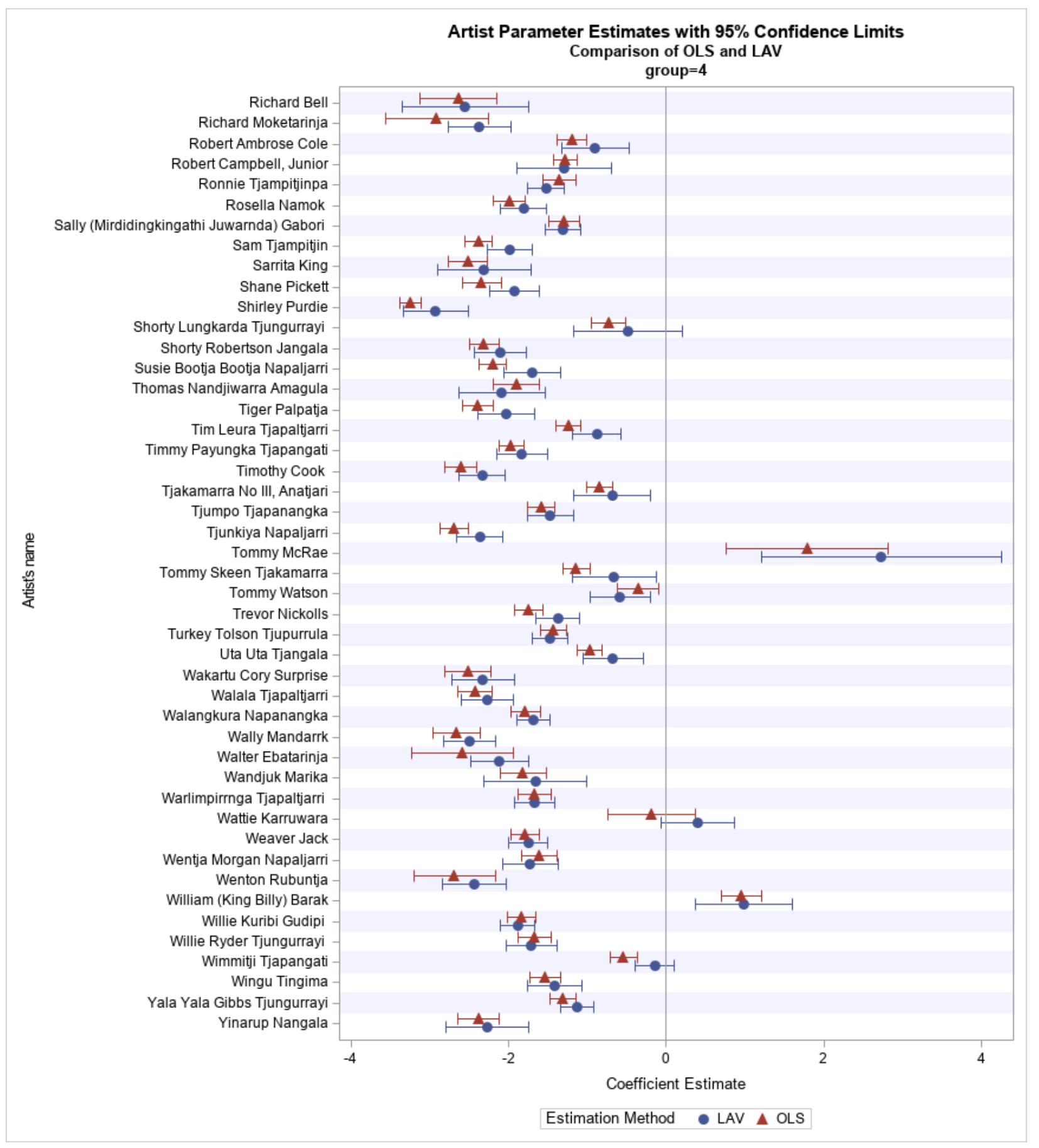




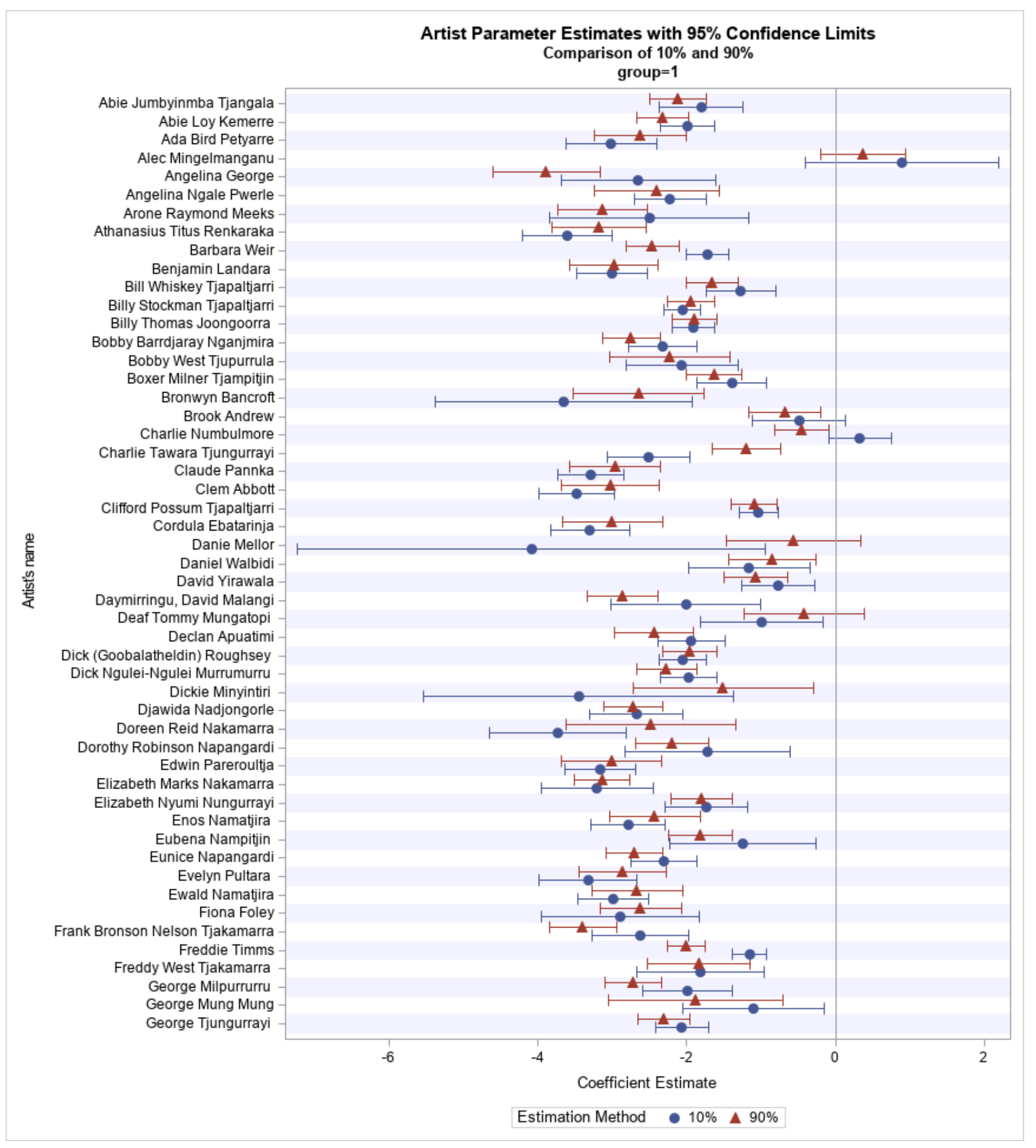




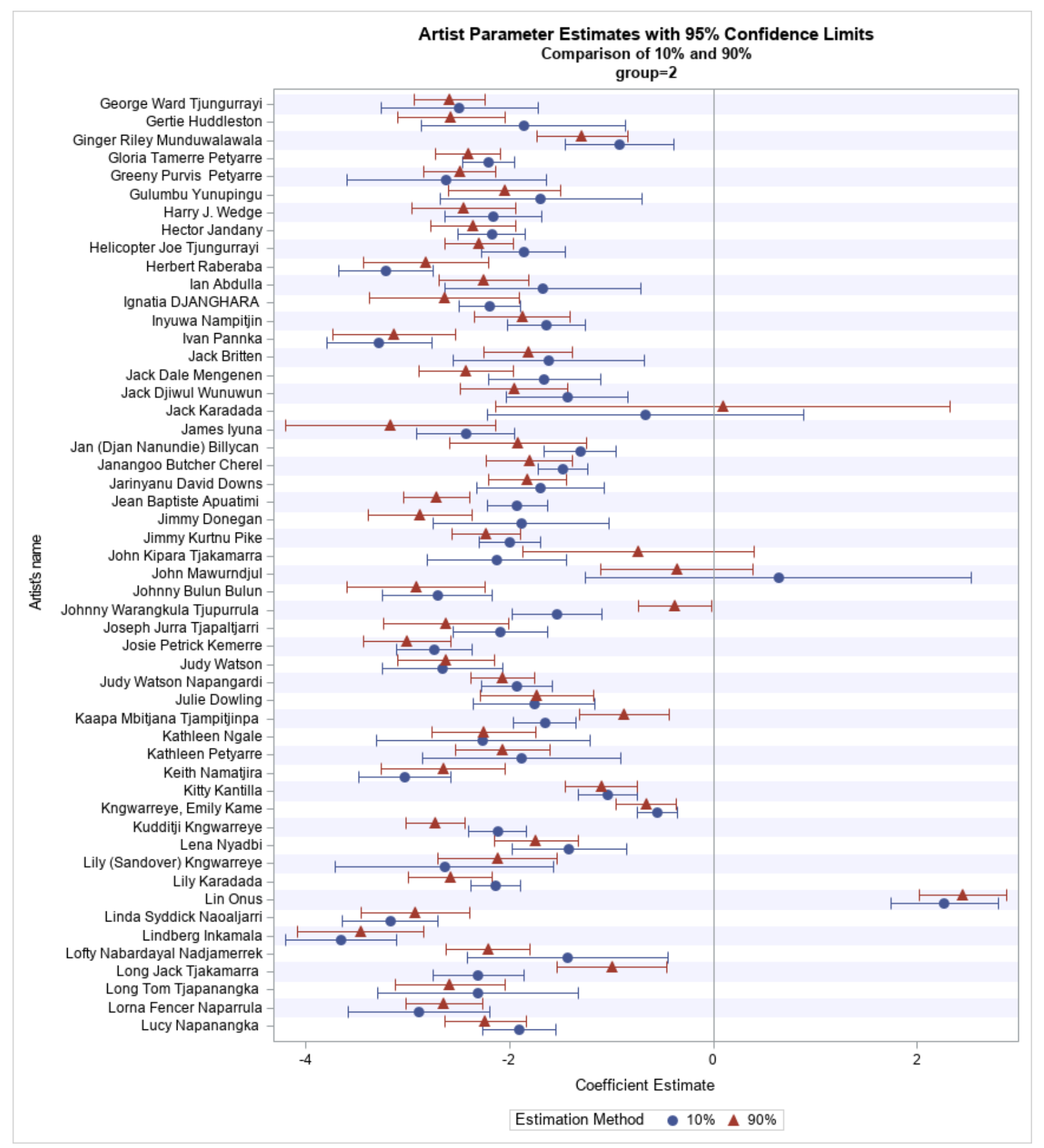




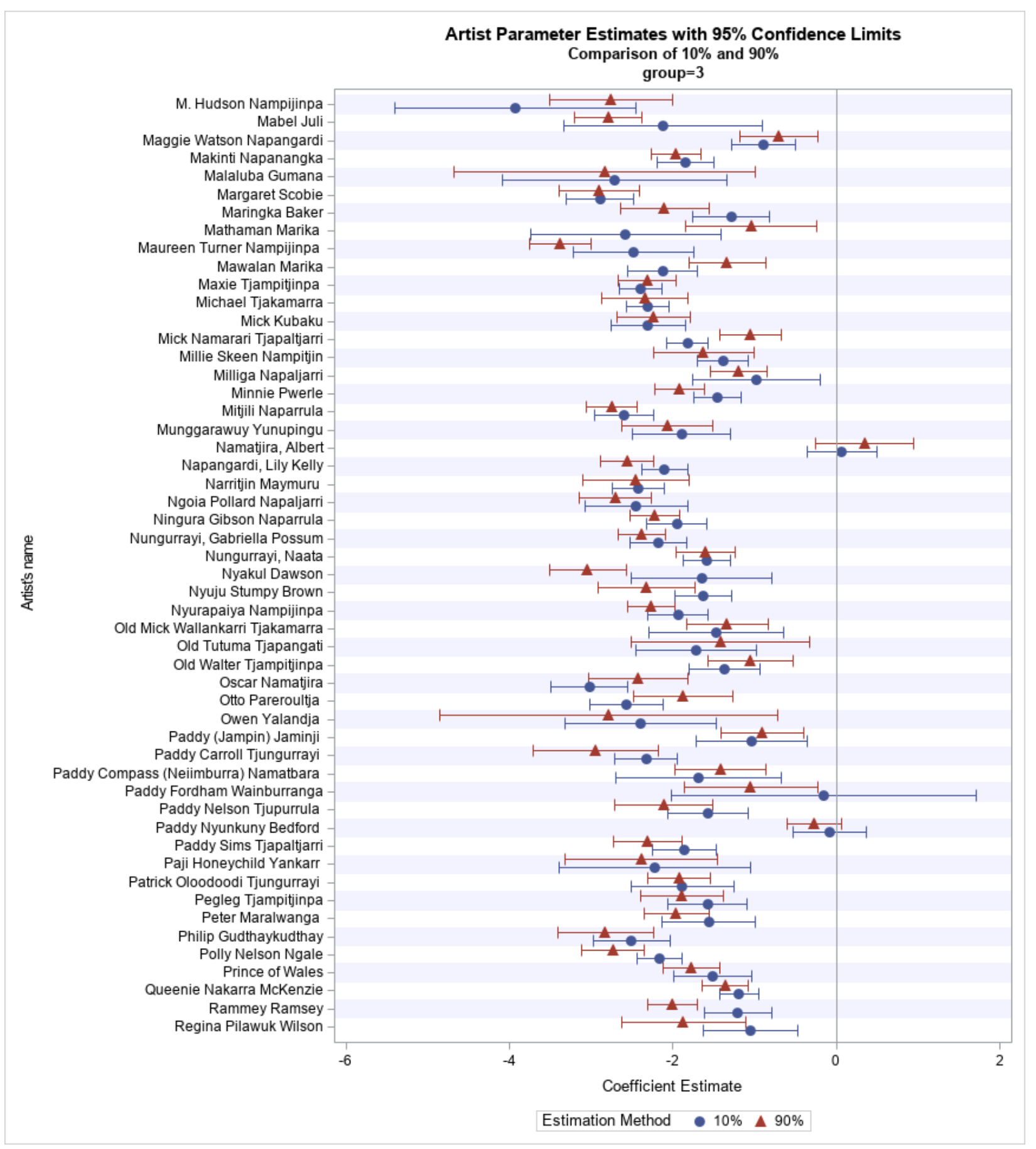




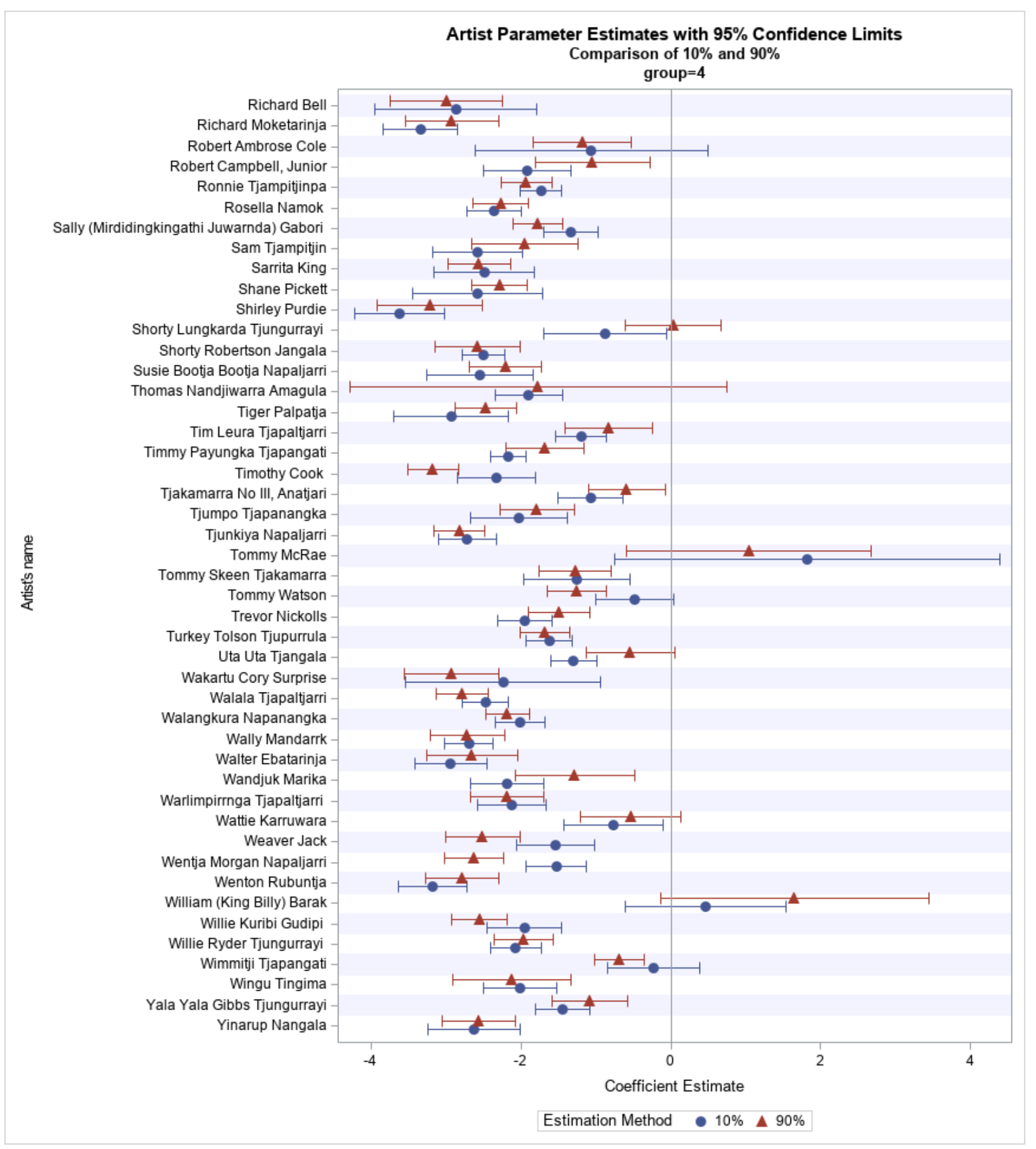




\section{University Library}

\section{- M M I E E R VA A gateway to Melbourne's research publications}

Minerva Access is the Institutional Repository of The University of Melbourne

Author/s:

Lye, JN;Hirschberg, JG

Title:

Investment in Australian Aboriginal Art

Date:

2020

Citation:

Lye, J. N. \& Hirschberg, J. G. (2020). Investment in Australian Aboriginal Art. Elsevier BV.

Persistent Link:

http://hdl.handle.net/11343/295957 